\title{
Epithelial-mesenchymal transition and nuclear $\beta$-catenin induced by conditional intestinal disruption of Cdh1 with Apc is E-cadherin EC1 domain dependent
}

\author{
Julia Matheson ${ }^{1, *}$, Claudia Bühnemann ${ }^{1, *}$, Emma J. Carter ${ }^{1}$, David Barnes ${ }^{1}$, Hans- \\ Jürgen Hoppe $^{1}$, Jennifer Hughes ${ }^{1}$, Stephen Cobbold $^{1}$, James Harper ${ }^{1}$, Hans \\ Morreau $^{2}$, Mirvat Surakhy ${ }^{1}$, A. Bassim Hassan ${ }^{1}$ \\ ${ }^{1}$ Tumour Growth Group, Oxford Molecular Pathology Institute, Sir William Dunn School of Pathology, University of Oxford, \\ South Parks Road, Oxford, United Kingdom \\ ${ }^{2}$ Department of Pathology, Leiden University Medical Centre, Leiden, The Netherlands \\ *These authors have contributed equally to this work \\ Correspondence to: A. Bassim Hassan, email: bass.hassan@path.ox.ac.uk \\ Keywords: E-cadherin, Apc, intestine, $\beta$-catenin, adhesion complex \\ Received: October 07, $2015 \quad$ Accepted: August 08, $2016 \quad$ Published: August 23, 2016
}

\section{ABSTRACT}

Two important protein-protein interactions establish E-cadherin (Cdh1) in the adhesion complex; homophilic binding via the extra-cellular (EC1) domain and cytoplasmic tail binding to $\beta$-catenin. Here, we evaluate whether E-cadherin binding can inhibit $\beta$-catenin when there is loss of Adenomatous polyposis coli (APC) from the $\beta$-catenin destruction complex. Combined conditional loss of Cdh1 and Apc were generated in the intestine, intestinal adenoma and adenoma organoids. Combined

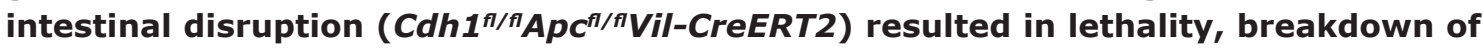
the intestinal barrier, increased Wnt target gene expression and increased nuclear $\beta$-catenin localization, suggesting that $E$-cadherin inhibits $\beta$-catenin. Combination with an intestinal stem cell Cre (Lgr5CreERT2) resulted in $A p c^{\Delta / \Delta}$ recombination and adenoma, but intact $C d h 1^{f / f}$ alleles. Cultured $A p c^{\Delta / \Delta} C d h 1^{f / f l}$ adenoma cells infected with adenovirus-Cre induced $C d h 1^{\pi / f}$ recombination $\left(C d h 1^{\Delta / \Delta}\right)$, disruption of organoid morphology, nuclear $\beta$-catenin localization, and cells with an epithelial-mesenchymal phenotype. Complementation with adenovirus expressing wild-type Cdh1 (Cdh1WT) rescued adhesion and $\beta$-catenin membrane localization, yet an EC1 specific double mutant defective in homophilic adhesion (Cdh1-Mut ${ }^{\text {W2A, }}{ }^{578 w}$ ) did not. These data suggest that $E$-cadherin inhibits $\beta$-catenin in the context of disruption of the APC-destruction complex, and that this function is also EC1 domain dependent. Both binding functions of E-cadherin may be required for its tumour suppressor activity.

\section{INTRODUCTION}

E-cadherin (Cdh1), a type 1 trans-membrane glycoprotein and a key structural and regulatory component of epithelial adherence junctions, links cell-cell binding to the dynamic cytoskeleton $[1,2]$. It has two principal protein binding interactions. The N-terminal EC1 domain of the extra-cellular immunoglobulin like domains (EC1-EC5) binds by a homophilic interaction in trans, with evidence for clustering in cis through weaker EC2 and EC3 twodimensional interactions $[3,4]$. The EC1 strand swapping mechanism occurs via calcium dependent binding of a tryptophan (Trp2) residue to the complimentary EC1 hydrophobic pocket, in a mechanism that also involves the $\mathrm{N}$-terminal 1-10 amino acids that contain a proline hinge region (residues 4-6) that facilitates Trp2 binding [3]. E-cadherin also constitutively binds $\beta$-catenin, $\alpha$-catenin and p120 catenin via a cytoplasmic tail domain, to form a complex that interacts with the attached actin cytoskeletal, and post-translational signalling components that regulate cell shape and motility [5].

E-cadherin is pre-bound to $\beta$-catenin as it exits the endoplasmic reticulum [6], suggesting that the cytoplasmic and membrane tethered pools of $\beta$-catenin may be plausibly 
regulated by E-cadherin. E-cadherin binds to $\beta$-catenin and a type $\mathrm{I} \gamma$ phosphatidylinositol phosphate kinase (PIPKI $\gamma$ ) in complex, and is stabilized at the juxta-membrane by p120 catenin and binding to the F-actin cytoskeleton. This complex functions to limit the normal ubiquitin mediated degradation of E-cadherin via Hakai [7-9]. The adhesion complex also localises p120-binding proteins including PLEKHA7 and a cytoplasmic DROSHA dependent pri-miRNA processing complex [10]. When $\beta$-catenin becomes detached from E-cadherin in the adhesion complex, it is then regulated in the cytoplasm by a destruction complex. This complex comprises Adenomatous Polyposis Coli (APC), glycogen synthase kinase 3 alpha/beta (GSK3 $\beta$ ), casein kinase 1 (CK1) and Axin1, and acts to limit the activation of $\beta$-catenin/Lef/TCF dependent gene expression $[11,12]$. Here we address whether the nuclear supply of $\beta$-catenin is also inhibited by E-cadherin, especially in the cancer specific context of loss of function of the APC associated destruction complex, and whether inhibition is extra-cellular adhesion domain dependent [5].

The mouse intestinal epithelium is an ideal model to genetically evaluate mammalian E-cadherin, APC and $\beta$-catenin function, as it is comprised of multiple parallel orientated crypt-villus functional adherent cell units that derive from a Wnt pathway regulated crypt stem cell compartment [13]. Leucine-rich repeat containing G-protein-coupled receptor (Lgr5) positive stem cells, flanked by Paneth cells, have a key function in maintaining the stem cell niche through $W n t$ growth factor activation of $\beta$-catenin stability $[14,15]$. Lgr5 positive columnar stem cells divide, renew and create an adherent population of transit amplifying cells that then undergo 4 to 5 cycles of cell division before differentiating and ascending up the villus $[15,16]$. Differentiated cells are comprised of four main epithelial lineages, enterocytes, goblet, entero-endocrine and Paneth cells. The latter migrate to the crypt base where they reside for 3-6 weeks, whereas the remaining cells escalate to the tip of the villi over 3-5 days prior to separation, anoikis and shedding, the latter associated with E-cadherin degradation [17, 18]. Importantly, $\beta$-catenin supply has been shown to be essential for crypt-villus homeostasis and the development of intestinal adenoma and carcinoma $[19,20]$.

Constitutive activation of the Wnt pathway is considered the driver for colorectal cancers (CRCs), most frequently due to loss of function of $A P C$ and disruption of the destruction complex (70-80\%), but also through specific gain of function $\beta$-catenin mutations (10-15\%), mutation of RNF43 (15-18\%) and more rarely through a DNA translocation that induces over-expression of R-Spondin $(<5 \%)$ [21-23]. In the absence of Wnt and $\mathrm{R}$-Spondin activation of a receptor complex comprised of Lgr5/Frizzled/Lrp6/ZNRF3, $\beta$-catenin is phosphorylated, ubiquitinated and degraded within the destruction complex, so precluding its nuclear localization with Lef1/ Tcf4 transcription factors [12]. APC truncation mutations and loss of heterozygosity, can result in complete loss of $\beta$-catenin destruction, leading to increased Tcf $/ \beta$-catenin downstream target gene expression, e.g. Myc, Axin2 and $C D 44$, effects that are reversible following $A p c$ reexpression [19, 20, 24]. Recently, evidence in mouse intestinal adenoma models suggest that E-cadherin is able to reduce the supply of stabilised $\beta$-catenin associated with a somatic gain of function mutation [25]. Moreover, genome wide association studies in colorectal cancer have identified SNP (rs9929218) of CDH1 as a germ-line modifier of colorectal cancer susceptibility and survival, yet the mechanistic basis of this association, and the potential interaction with multiple subsequent somatic acquired mutations, remains unknown [26, 27].

To evaluate the combined functional effects of $C d h 1$ and $A p c$ in the intestine, we utilised conditional genetic models. Conditional alleles (loxP) of genes $C d h 1$ and $A p c$ were combined using breeding, and recombination induced by additional expression of intestinal specific Cre transgenes. Here, we denote the germ-line determined detection of homozygote loxP alleles as $C d h 1^{f / f l}$ and $A p c^{f /}$ ${ }^{f}$. Where somatic tissues have been directly tested for the presence of the resulting Cre induced recombined alleles using PCR, we denote the alleles as $C d h 1^{4 / \Delta}$ and $A p c^{\Delta / \Delta}$. Adenoma organoid cultures derived directly from adenoma tissue in vivo, where alleles were recombined (e.g. PCR positive for $A p c^{\Delta / \Delta}$ ), were then genetically complemented with $C d h 1$ expressed using adenoviral expression vectors, and phenotypes evaluated. Our findings suggest significant E-cadherin inhibition of $\beta$-catenin supply in the context of $A p c$ genetic disruption. These data have functional mechanistic implications for invasive human cancers with co-existing $A P C$ and $C D H 1$ loss of function.

\section{RESULTS}

\section{Combined intestinal Apc and Cdh1 loss of function show additive phenotypes}

The Vil-Cre transgene is expressed from E9 in the visceral endoderm of the yolk sac and by E12.5 in the developing intestinal epithelium [28]. Assessment of genotypes from breeding of $\mathrm{Cdh1^{+ff }}$ Vil-Cre $\times \mathrm{Cdh1}^{+1}$ ${ }^{A}$ Vil-Cre, or Cdh1 $1^{f l f l}$ Vil-Cre $\times C d h 1^{+f f}$ Vil-Cre animals showed a highly significant deviation from the expected Mendelian ratios at birth (P0, see Supplementary Figure S1a). Expected ratios and normal morphology of embryos were observed at E10.5, but by E11.5-E12.5 there were increased numbers of embryonic resorptions (Supplementary Figure S1b). Following Cre-mediated recombination, $C d h 1^{\Delta / \Delta}$ Vil-Cre embryos appeared smaller than littermate controls, and frequently lacked extraembryonic membranes, and by E12.5, had reduced yolk sac E-cadherin labelling (Supplementary Figure S1c) [29].

To sidestep embryonic lethality, a tamoxifen inducible intestinal Vil-CreER $R^{T 2}$ transgene was then combined with Cdh1 loxp alleles [28]. Following induction with $40 \mathrm{mg} \cdot \mathrm{kg}^{-1}$ 
tamoxifen administered by intra-peritoneal injection on five sequential days (low dose tamoxifen) or $200 \mathrm{mg} \cdot \mathrm{kg}^{-1}$ on two sequential days (high dose tamoxifen), adult animals either remained well $\left(C d h 1^{+/+} V i l-C r e E R^{T 2}, C d h 1^{+f l} V i l-\right.$ $C r e E R^{T 2}$ ) or became sick (Cdhl $1^{\text {flflf }}$ Vil-CreER ${ }^{T 2}$ ) after 4-5 days, with weight loss, dehydration and diarrhoea (Figure 1a). At post-mortem, Cdh $1^{\text {flfl}}$ Vil-CreER ${ }^{T 2}$ animals had developed peritoneal exudates, grossly dilated intestines that were also significantly shortened and hyperaemic (Supplementary Figure S2a,b). Genotyping of the Cdh1 allele, labelling for YFP and E-cadherin, and RT-QPCR, all confirmed efficient intestinal recombination $\left(C d h 1^{\Delta / \Delta}\right)$ with $<50 \%$ Cdh1 mRNA expression (Supplementary Figure S2c). $C d h 1^{\Delta / 4}$ Vil-CreER ${ }^{T 2}$ small intestines had distorted cryptvillus architecture, loss of the well-defined crypt-villus boundary, loss of uniform cell stacking along the cryptvillus axis with mucus pooling, villus tufting, epithelial cell shedding and inflammatory infiltrates (Figure 1b). RT-QPCR of spleen material for bacterial ribosomal S16 RNA (a component of the 30S small subunit of prokaryotic

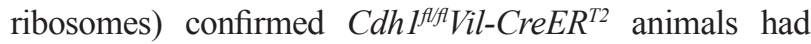
evidence of systemic bacteraemia secondary to breakdown of the intestinal barrier (Supplementary Figure S2d).

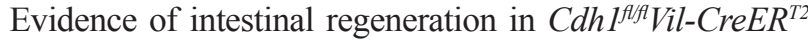
animals was supported by an increase in crypt cellular proliferation Cdh $1^{f l f}$ Vil-CreER ${ }^{T 2}$ labeled with BrdU, and confirmed by Ki-67 immuno-labelling (Figure 1c). Apoptosis assessed by cleaved caspase-3 labelling was also significantly increased in $\mathrm{Cdh}^{4 / \Delta} \mathrm{Vil}-\mathrm{CreER}{ }^{T 2}$ villi (Figure 1d). Significant increases in the Wnt target genes, $c-M y c$, $C D 44$ and EphB3 were detected, but with decrease of Axin2 mRNA (Figure 2c). Axin2 is generally considered to be a reliable Wnt pathway reporter (http://www.stanford.edu/ group/nusselab/cgi-bin/wnt/main), and is used in preference to transgenic Wnt reporters [30]. Paneth cells were scattered along the crypt-villus axis (Supplementary Figure S3a,b), goblet cells (Mucin 2) and enteroendocrine cells (Chromogranin A) were also significantly reduced in number and predominantly located in the upper villus compared with wild-type animals (Supplementary Figure S3a,b). Of

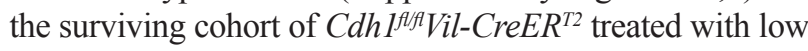
dose tamoxifen and aged to one year, neither adenoma nor

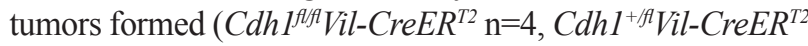
$\mathrm{n}=6, C_{d h 1^{+/+}}$Vil-CreER $R^{T 2} \mathrm{n}=3$ ).

We next investigated the consequence of Apc loss of function combined with $C d h 1$. Intestinal activation of Vil$\mathrm{CreER}^{T 2}$ in $A p c^{\mathrm{Alfl}}$ resulted in a phenotype similar to that previously characterized using $A h C r e E R^{T}$ and $\mathrm{Vil}-\mathrm{CreER}{ }^{T 2}$ [24]. Apc ${ }^{\text {Alfl} V i l-C r e E R ~}{ }^{T 2}$ animals became unwell with weight loss and diarrhoea five days following tamoxifen treatment (Figure 1a). Unlike Cdh $1^{f l f l}$ Vil-CreER ${ }^{T 2}$, there was no evidence of intestinal shortening or inflammation (Supplementary Figure S2a,b). For Apc ${ }^{A l f l} V_{i l}-C r e E R^{T 2}$ intestine, expanded crypt zones with densely stacked cells, increased apoptotic nuclei, and a clear boundary between the proliferative zone and the villus, were observed (Figure 1b,c).
When $A p c^{A l f l}$ and $C d h 1^{f l f l}$ were then combined with Vil$C r e E R^{T 2}$, rapid phenotypic changes with weight loss, diarrhoea, intestinal dilatation and shortening, all occurred within 5 days (Supplementary Figure S2). Histology of the intestines showed combined phenotypic features attributable to both $A p c^{\Delta / \Delta}$ and $C d h 1^{\Delta / \Delta}, e . g$. an expanded crypt zone, disorganized crypt structure and crypt-villus boundary, and shedding of cells from the villus tip (Figure 1b). $A p c^{\Delta / \Delta} C_{d h 1^{4 / \Delta}}$ Vil-CreER ${ }^{T 2}$ small intestines labelled with an E-cadherin antibody showed areas of loss that were particularly marked in the villus region, with patchy loss in the expanded crypt zone and retained labelling in some cells (Figure 1c,d). In Apc $c^{4 / \Delta}$ Vil-CreER ${ }^{T 2}$ intestines, the cryptvillus boundary was labelled by c-Myc and EphB2, but in $A p c^{4 / 4} C_{d h 1^{4 / 4}}$ Vil-CreER ${ }^{T 2}$ intestines this had a less defined border (Supplementary Figure S4a,b,c). As with $A p c^{4 /}$ ${ }^{4}$ Vil-CreER ${ }^{T 2}$ intestines, there was significantly increased proliferation and apoptosis in the expanded crypt zone, but this also extended into the villi as in $C d h 1^{\text {fl/fl }}$ Vil-CreER $R^{T 2}$ (Figure 1d). The most striking feature appeared the localization of $\beta$-catenin, where marked increases in cytoplasmic and nuclear $\beta$-catenin were observed in the $A p c^{4 / \Delta} \mathrm{Cdh}^{4 / \Delta}$ Vil-CreER ${ }^{T 2}$ intestinal crypts and villi (Figure $2 \mathrm{a}, \mathrm{b})$. Nuclear $\beta$-catenin was quantified and was present in a significantly higher percentage of cells in both the crypt and the villi (Figure 2b). RT-QPCR showed expected upregulation of $W n t$ target genes including $c-M y c$ and CD44 $(p=0.02$ and 0.0007 respectively, Figure 2c), although Axin 2 appeared to have increased to a lesser extent when comparing $\mathrm{Apc}^{\Delta / \Delta} \mathrm{Cdh}^{4 / \Delta}$ Vil-CreER ${ }^{T 2}$ to Apc $\mathrm{C}^{\Delta / \Delta}$ Vil-CreER ${ }^{T 2}$ intestinal controls ( $\mathrm{p}=0.007$, Figure $2 \mathrm{c})$. The increase in mRNA was confirmed by labelling for CD44, c-Myc, EphB2 and EphB3 (Supplementary Figure S4 a,b,c). Overall, these data suggest that E-cadherin inhibits nuclear $\beta$-catenin localization when there is Apc loss of function, and that this correlates with gene expression, although the effect on Axin 2 appeared different and unexpected (Figure 2c and Supplementary Figure S5).

Lysozyme labelled Paneth cells were re-positioned away from the crypt base but were still confined to the expanded proliferative zone, whereas goblet and entero-endocrine cell numbers appeared decreased in $\mathrm{Apc}^{\mathrm{A} / \Delta} \mathrm{Cdh}^{4 / \Delta} \mathrm{Vil}_{-C \mathrm{CreER}}{ }^{T 2}$ intestines compared to $A p c^{\Delta / \Delta}$ Vil-CreER ${ }^{T 2}$ controls (Supplementary Figure S3a,b). In $A p c^{4 / \Delta} C d h 1^{4 / \Delta} V i l-C r e E R^{T 2}$ intestines, cells appeared less densely packed in the expanded proliferative zone with lower total number of cells along the crypt-villus axis (Figure 1c). The proliferative zone was expanded throughout the crypts and villi as a result of $A p c^{\Delta / \Delta}$ and $C d h 1^{\Delta /}$ ${ }^{4}$ indicated by BrdU labelling (Figure 1c). Apoptosis was also markedly increased in the expanded proliferative zone of $\mathrm{Apc}^{\mathrm{S} / \Delta} \mathrm{Cdh}^{\mathrm{s} / 4} \mathrm{Vil}$-CreER ${ }^{T 2}$ intestines, with non-adherent cells displaying high expression of cleaved caspase 3 cells in the intestinal lumen (Figure 1d).

Gene Set Enrichment Analysis (GSEA) was performed on intestinal RNA microarray data derived from all genotypes and using all of the gene sets in the Molecular Signatures 
Database v4.0 (Broad Institute). We identified the leading edge sets (LES) from this analysis, containing 955 genes, including those associated with Wnt pathway activation, and interrogated these data further by extracting the genes which occurred most frequently in LES (Supplementary Figure S5). Aside from confirming Wnt pathway genes, the most enriched was Areg (Amphiregulin), coding for an EGF receptor ligand, upregulated in $A p c^{4 / 4} \mathrm{Cdh1}^{4 / 4} \mathrm{Vil}_{-\mathrm{CreER}}{ }^{T 2}$ intestines. We also selected genes that are present in the most recent Sanger COSMIC Cancer Genes census (http://cancer. sanger.ac.uk/cancergenome/projects/census/), and those with a Gene Ontology (GO) term annotated as 'inflammatory'. A total of 5 genes were annotated for both cancer and inflammation: Fcgr2b, Egfr, Tnfaip3, Fas and Myd88.

\section{Combined Apc and Cdh1 recombination induced intestinal adenoma}

To further investigate the genetic interactions between $A p c$ and $C d h 1$ in the intestine, we next combined genotypes in intestinal adenoma. Heterozygote alleles were combined $\left(A p c^{f / /} C d h I^{f l /}\right.$ Vil-CreER $\left.R^{T 2}\right)$ and intestinal adenoma induced by tamoxifen and results compared to that of germ-line heterozygotes $C d h 1^{+/}$combined with the $A p c^{\mathrm{Min} /+}$ model (Supplementary Figure S6). Our initial results suggested that $C d h 1$ heterozygosity might promote Apc loss of function induced adenoma formation. We observed, however, a strain dependent effect of $C d h 1$ with both $A p c^{\mathrm{Min} /+}$ (129Ola) and $A p c^{f /+}(\mathrm{B} 6 \mathrm{D} 2) \mathrm{Vil}-\mathrm{CreER}^{T 2}$, as a b
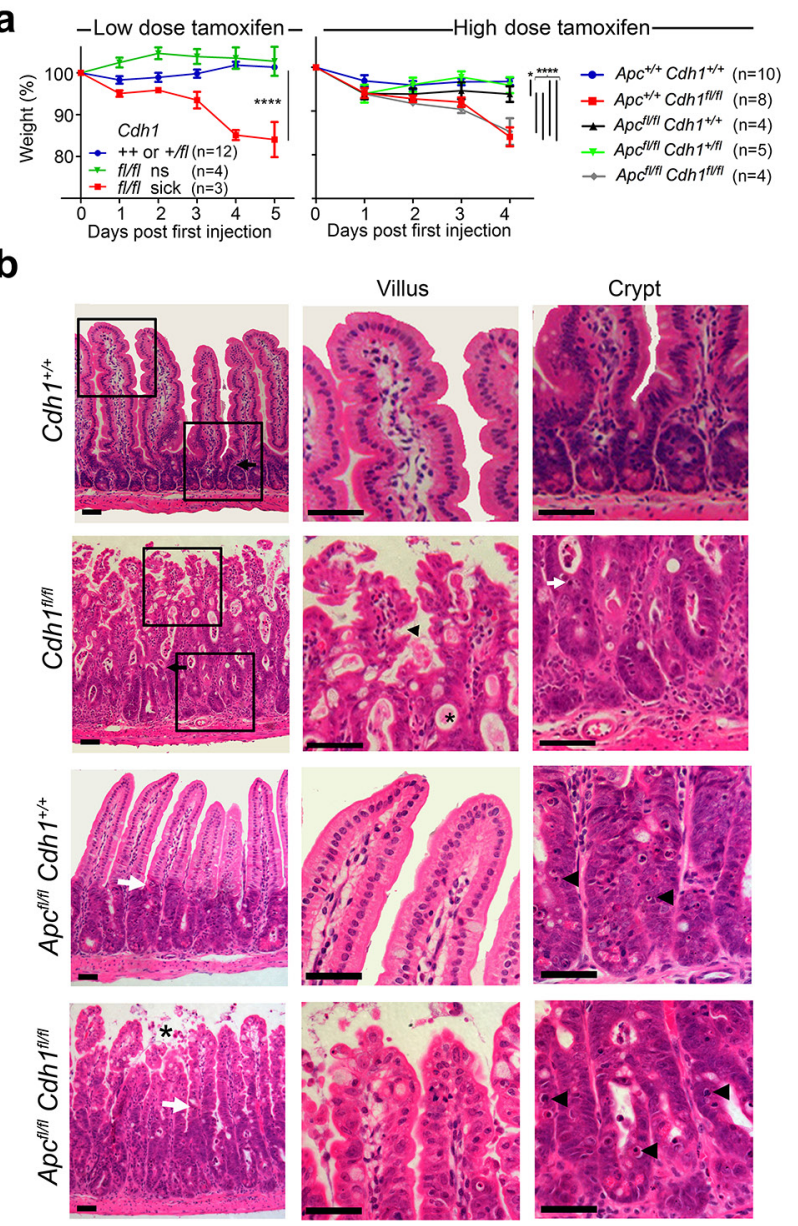

C
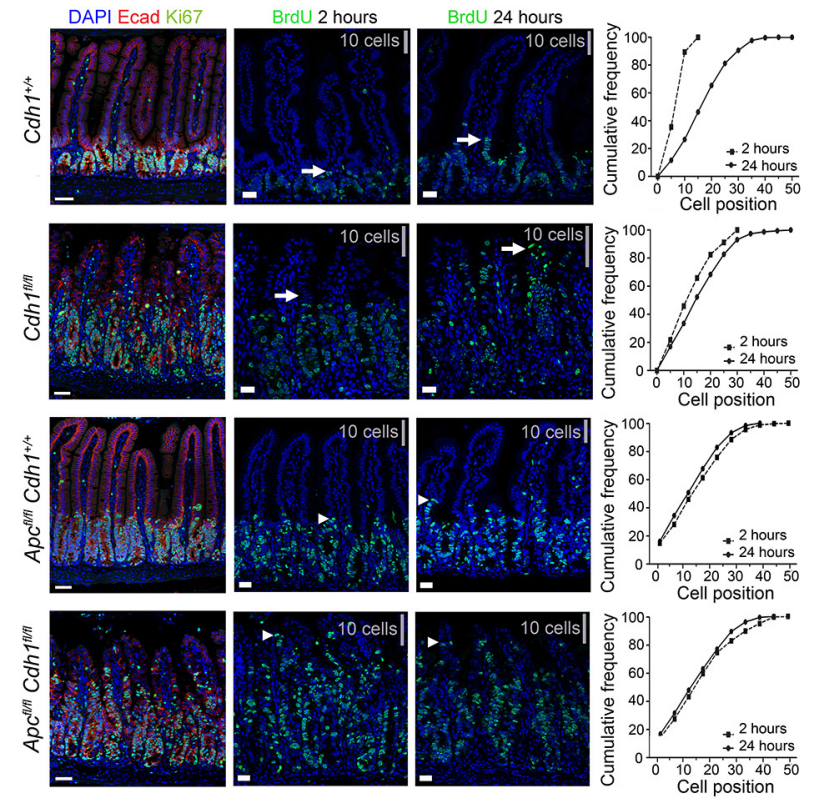

d
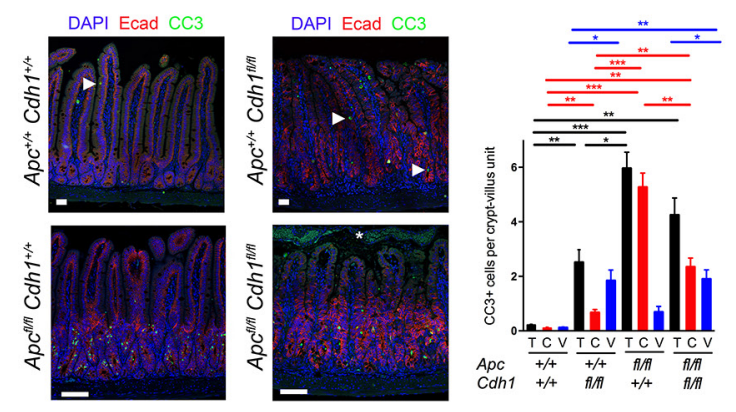

Figure 1: Intestinal phenotype following conditional $\mathrm{Cdh} 1$ and $\mathrm{Apc}$ homozygous disruption with $\mathrm{Vil}$-CreER $\boldsymbol{R}^{T 2}$ a. Animal weight (\% of pre-injection) after intra-peritoneal injection with either low (40 mg.kg $\left.{ }^{-1} \mathrm{~d} 1-5\right)$ or high dose tamoxifen (200 mg.kg-1 $\left.\mathrm{d} 1-2\right)$, to generate $C d h 1^{4 / \Delta}$ with and without $A p c^{4 / 4}$. Animals became either sick or not-sick (ns). ANOVA with Bonferroni post test for each genotype $\left( \pm\right.$ SEM). ${ }^{*} \mathrm{p}<0.05 . * * * \mathrm{p}<0.001$. b. H and E staining of small intestine, with high power views of villus and crypt. Black and white arrows locate the crypt-villus boundary under low power. In $C d h 1^{\Delta / 4}$, black arrowhead villus tufting, *mucus pooling, white arrow apoptotic nuclei. In $A p c^{\Delta / 4} C d h 1^{\Delta / \Delta}, *$ villous shedding, black arrow heads indicate more frequent apoptotic nuclei. c. Intestinal proliferation detected with BrdU labelling following injection either 2 or 24 hours prior to dissection, compared to Ki-67. White arrows/ arrowheads indicate the leading edge of BrdU labelling, grey bars indicate distance spanned by 10 crypt-villous cells. Cumulative frequency plots quantifying BrdU labelling, with cell position on the crypt-villus axis from the crypt base. d. Labelling for cleaved caspase 3 (CC3), number of positive cells per crypt-villus unit, ${ }^{*}=$ shed cells in the intestinal lumen that are CC3 positive but not counted, white arrowhead positive labelling. Quantification of CC3 positive cells, total (black), crypt (red) and villi (blue), $\geq 3$ animals per genotype and $\geq 20$ crypt-villus units analysed per animal, \pm SEM. Student's t- test, ${ }^{*} \mathrm{p}<0.05,{ }^{* *} \mathrm{p}<0.01, * * * \mathrm{p}<0.005$. Image bars $50 \mu \mathrm{m}$. 
the differences in adenoma counts and survival between either $A p c^{M i n /+}$ or $A p c^{A /+}$ diminished when the alleles were back-crossed from a mixed background to C57BL/6J, consistent with the presence of non- C57BL/6J modifier alleles [31]. Moreover, these data suggest the decreased survival and greater adenoma frequency previously reported with $C d h 1$ heterozygosity may be because of cosegregating modifiers from a mixed strain background, as well as being potentially $C d h 1$ dependent [32].

We next combined $A p c^{A l f l} C d h 1^{f l / f l}$ and $A p c^{A l f l} C d h 1^{+/+}$ with a Cre driven by the promoter of the $W n t$ response gene and stem cell marker Lgr5, (Lgr5-EGFP-IRES-CreER ${ }^{\mathrm{T} 2}$ or Lgr5CreER ${ }^{T 2}$ ) $[14,33]$. Recombination rates in intestinal epithelial cells are lower overall with this transgene (56\%), but highly specific for $\operatorname{Lr} 5$ stem cells. Rapid adenoma development within 3-5 weeks occurs as a result of biallelic $A p c^{\Delta / \Delta}$ recombination. Surprisingly, comparison of overall survival and adenoma formation between $A p c^{A l}$

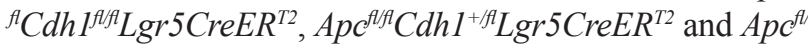
${ }^{f l} \mathrm{Cdh} 1^{+/+} \operatorname{Lgr} 5 \mathrm{CreER}{ }^{T 2}$ showed no significant differences (Figure 3a). Wnt dependent gene expression in adenoma was markedly increased as observed in the small intestine (Figure 3b). Histological grading of small intestinal adenoma showed low-grade dysplasia in all genotypes, with caecal tumours rarely exhibiting high-grade dysplasia and carcinoma in situ (Figure 3c,d). Genotyping of adenoma showed most retained $C d h 1$ non-recombined $\left(C d h 1^{f / f l}\right)$ alleles, with a minority of adenoma showing evidence of recombination by PCR, although similar detectable $C d h 1$ mRNA expression was seen irrespective of genotype (Figure $3 b$, Supplementary Figure S7c). E-cadherin labelling of adenoma revealed some areas of reduced E-cadherin, but no areas of complete loss within adenoma from $A p c^{A /}$ ${ }^{A l} \mathrm{Cdh}^{\mathrm{flfl}} \mathrm{Lgr} 5 \mathrm{CreER}{ }^{T 2}$ genotyped mice (Supplementary Figure S7d). These data suggest that there was either inefficient recombination, or frequent recombination but negative selection of double homozygote recombined cells $\left(A p c^{\Delta / \Delta} C d h 1^{\Delta / \Delta}\right)$.

In order to test whether recombination could be further induced, we re-challenged animals with $A p c^{\Delta /}$ ${ }^{4} C d h 1^{\text {fllf }} \operatorname{Lgr} 5 \mathrm{CreER}{ }^{T 2}$ adenoma with a second series of tamoxifen injections, in the expectation that as $\operatorname{Lgr} 5$ expression is also activated by the Wnt pathway, repeated recombination would increase the detection of $C d h 1^{\Delta / 4}$ within adenoma, [14, 34]. Three animals re-injected at 16 days after the first round of tamoxifen injections, showed an expected increase in small sized adenoma as a result of a further wave of $A p c^{A / f l}$ recombination $\left(A p c^{\Delta / \Delta}\right)$. All three animals deteriorated rapidly however, two within 4 days of tamoxifen re-challenge, yet all had a similar adenoma counts (Supplementary Figure S7a). The increase in the number of smaller adenoma after re-challenge was expected, as recombination of $A p c^{f / f}$ would increase the number of adenoma initiated, but this effect was unlikely to account for the rapid deterioration of the animals (Supplementary Figure S7a). Necropsy revealed evidence a
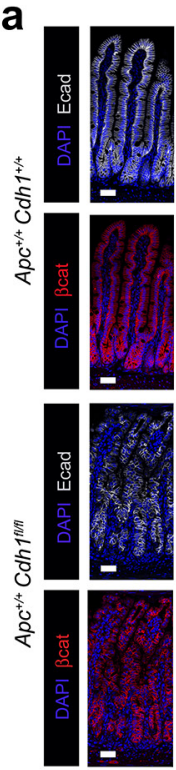

villus
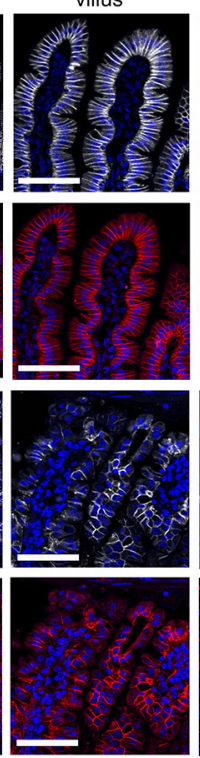

crypt
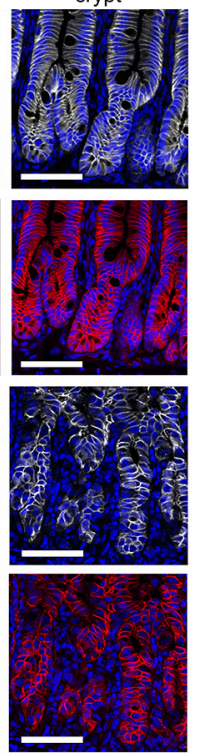
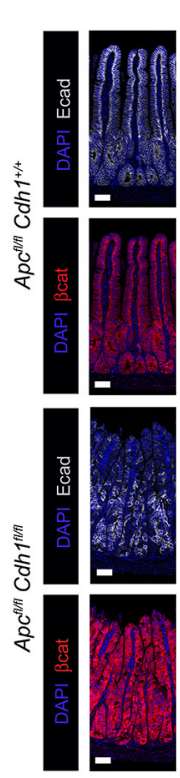

villus

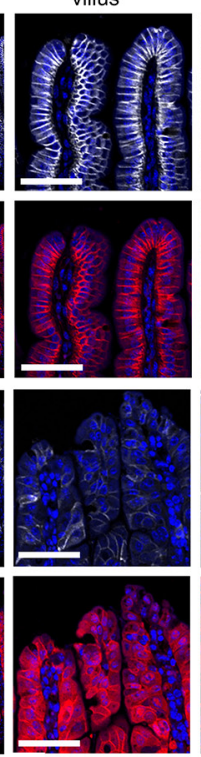

crypt

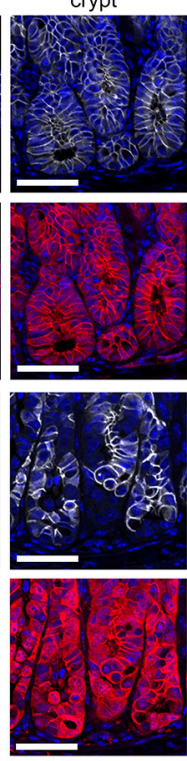

b

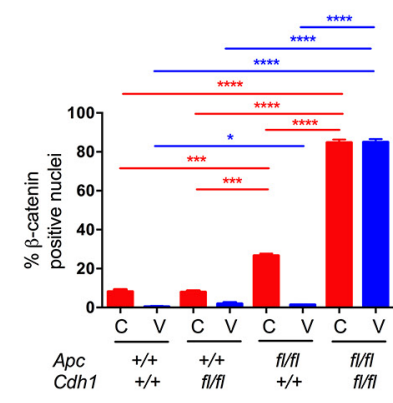

C

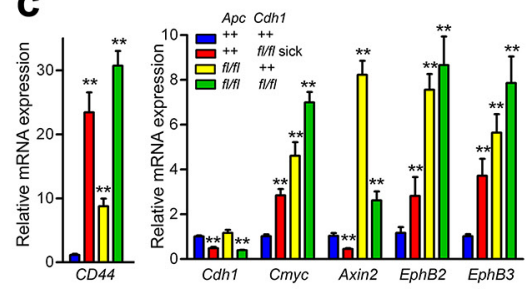

Figure 2: Combined Vil-CreER ${ }^{T 2}$ with $A p c$ and $C d h 1$ homozygous floxed alleles results in $\beta$-catenin nuclear localization and activation of $\boldsymbol{W n t}$ target genes. a. Localization of E-cadherin and $\beta$-catenin in the small intestine from $\mathrm{Apc}^{+/+} \mathrm{Cdh}^{+/+} \mathrm{Vil}-\mathrm{CreER}^{T 2}$,

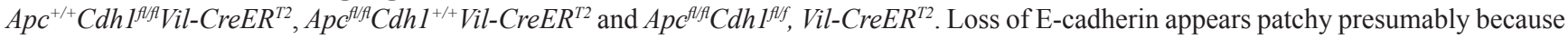
of intestinal regeneration. $A p c^{4 / 4} C d h 1^{4 / 4} \mathrm{Vil}-\mathrm{CreER} R^{T 2}$ is associated with marked cytoplasmic and nuclear localization of $\beta$-catenin. Scale bars $50 \mu \mathrm{m}$. b. Quantification of nuclear $\beta$-catenin in crypt or villus from each genotype ( $\mathrm{n}=3$ animals per genotype, $>1000$ cells counted per genotype $( \pm \mathrm{SEM})$. Student t-test. ${ }^{*} \mathrm{p}<0.05,{ }^{* *} \mathrm{p}<0.01,{ }^{* * *} \mathrm{p}<0.005, * * * * \mathrm{p}<0.001$. (c) RT-QPCR of whole intestinal samples for $W n t$ target genes. ( $\mathrm{n} \geq 3$ mice per genotype) relative to Actb and Hprt expression and wild-type small intestine. Apc and Cdh1 homozygous floxed intestinal cells over-express $W n t$ target genes. Student's t-test $( \pm \mathrm{SEM}) * * \mathrm{p}<0.01$. 

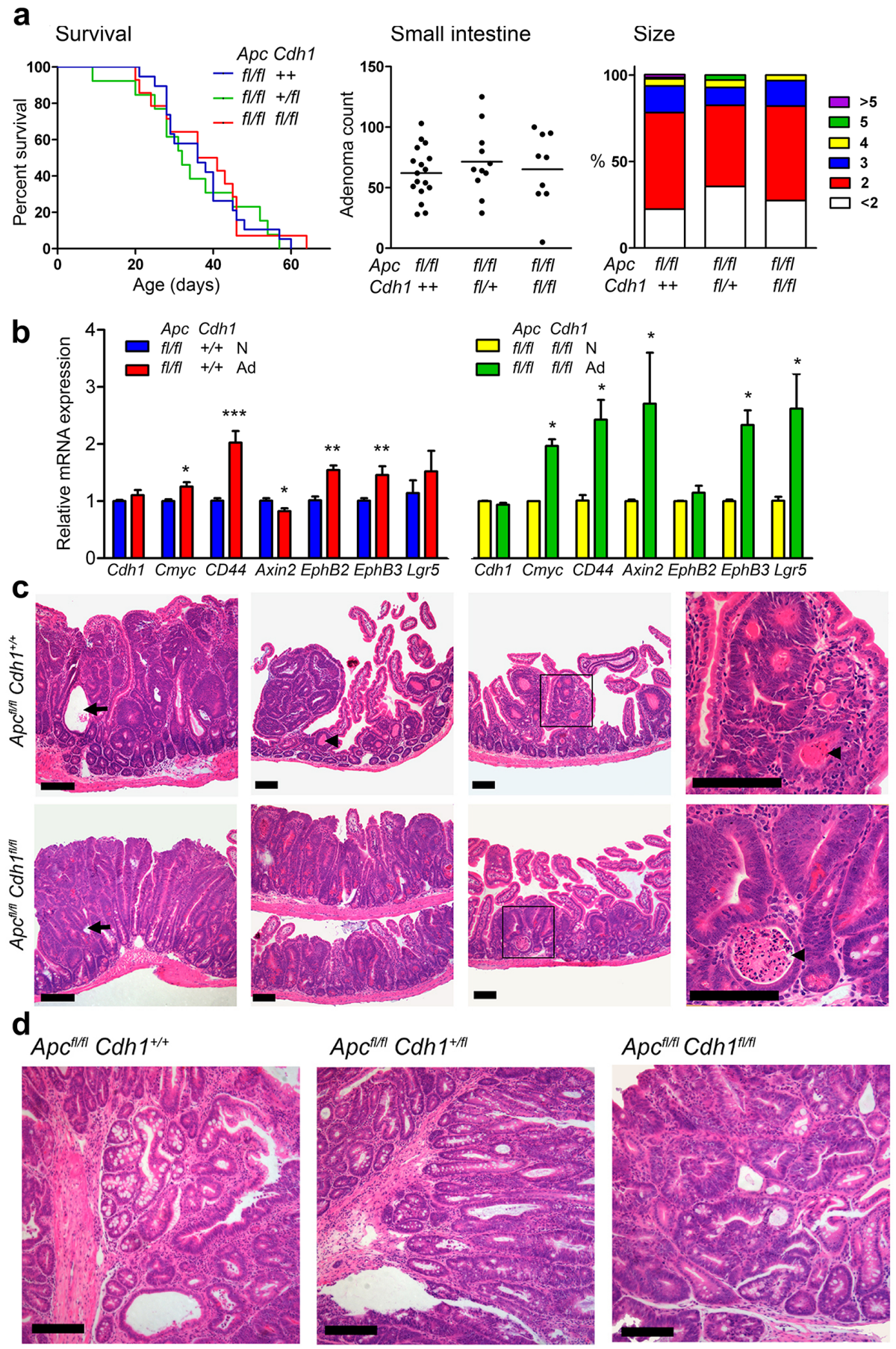

Figure 3: $\mathbf{L g r 5 C r e E R ^ { T 2 }}$ induces $A p c^{A f f}$ floxed intestinal adenoma without co-floxed $C d h 1$ alleles. a. Survival analysis following combination of $A p c^{A / A} C d h 1^{A / f /}$ with $\operatorname{Lgr} 5 \mathrm{CreER^{T2 }}$. Induced $A p c^{A / 4}$ adenoma reduced survival. No significant differences were

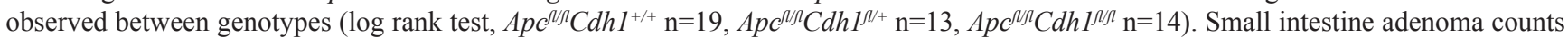
and adenoma diameters $(\mathrm{mm})$ in mice sacrificed at the humane endpoint, showing no significant difference between genotypes. One-way

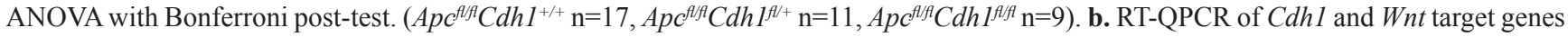
in caecal adenoma (Ad) compared with normal caecal tissue $(\mathrm{N})$. Up-regulation of relative expression of $W n t$ target genes, normalized with $\beta$-actin and Hprt (Normal intestine control gene expression not significantly different; $\beta$-actin $C T=16.0 \pm 0.58$ vs $16.5 \pm 0.76$, Hprt $C T=23.9 \pm 0.51$ vs $24.0 \pm 0.53$ for $A p c^{A / f} C d h 1^{++/}[\mathrm{n}=8]$ and $A p c^{A t / A} C d h 1^{\nexists A f}[\mathrm{n}=5]$, respectively), in adenomas genotypes. Note $C d h 1 \mathrm{mRNA}$ expression persists indicating lack of $C d h 1$ floxed alleles. $\mathrm{n}>3$ animals. Student's t-test $( \pm \mathrm{SEM}) .{ }^{*} \mathrm{p}<0.05{ }^{*}{ }^{*} \mathrm{p}<0.01 .{ }^{*} * * \mathrm{p}<0.001$. c.

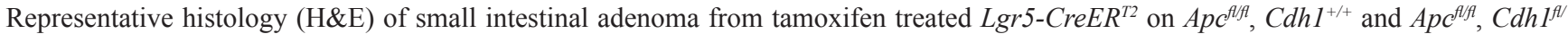
${ }^{A}$ backgrounds showing sessile small intestinal adenomas, diffuse adenomatosis, necrosis(arrowheads, necrotic cellular debris within the lumen of neoplastic glands) and cystic changes (arrows) in both genotypes. d. Representative histology (H\&E) of caecal tumours from the same animals showing a similarspectrum of adenoma grades. Scale bars 100 $\mu$ m. See Supplementary Figure S7 for Tamoxifen re-challenge. 
of peritonitis, suggesting intestinal perforation, with histological examination showing areas of blood, necrosis and cell death within adenoma consistent with the potential for a localised $C d h 1^{\Delta / \Delta}$ induced loss of the intestinal barrier within adenoma (Supplementary Figure S7b). Overall, these data suggest that $A p c^{\Delta / \Delta} C d h 1^{\Delta / \Delta}$ adenoma cells could be generated within existing adenoma, but that these cells had either impaired survival or were rapidly removed, as they were not frequently detected.

\section{Conditional Cdh1 disruption in Apc induced adenoma cells following in vitro organoid culture}

In view of the lack of detectable $C d h 1^{\text {flft }}$ recombination in vivo, we isolated $A p c^{\Delta / A} C d h 1^{f l / t}$ adenoma cells from the small intestine, and generated adenoma suspensions for in vitro organoid culture [15, 35, 36]. Exposure to tamoxifen to reactivate $\operatorname{Lgr} 5 \mathrm{CreER}{ }^{T 2}$ in culture failed to result in recombined $C d h 1^{\Delta / \Delta}$ alleles, confirmed by E-cadherin labelling and PCR genotyping. In order to express higher levels of Cre, transfection of adenoma cell suspensions was performed with an adenovirus-Cre, here with Cre and GFP expressed using a CMV promoter (Ad-Cre-GFP). Following transfection, we detected biallelic $C d h 1$ recombined alleles $\left(C d h 1^{4 / \Delta}\right)$, and a marked phenotypic change in organoid structure, with fragmentation and appearance of cells remote from the periphery of the organoids (Figure 4a, Supplementary Figure S8). Most

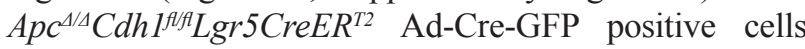
expressed high levels of Cre when labelled with an antiCre antibody, with significant associated loss of E-cadherin labelling (Supplementary Figure S8). Within 3 days, many Ad-Cre-GFP transfected $A p c^{4 / 4} \mathrm{Cdh}^{f l f t} \mathrm{Lgr}^{\mathrm{CC} C E R^{T 2}}$ adenoma organoids lost the spherical morula-like structure and developed surrounding regions with spindle like cell morphology (Figure 4a-f, Figure 5a). Despite the disruption of some of the $A p c^{4 / A} C_{d h 1^{f l f}} \operatorname{Lgr} \mathrm{CreER}^{T 2}$ organoids, we confirmed that the remaining intact $A p c^{4}$ ${ }^{4} \mathrm{Cdh}^{\mathrm{All} / \mathrm{Lgr}} 5 \mathrm{CreER}{ }^{T 2}$ and $\mathrm{Apc}^{4 / 4} \mathrm{Cdh}^{+/+} \operatorname{Lgr}_{5} \mathrm{CreER} \mathrm{R}^{T 2}$ organoids grew at similar rates (Figure $4 \mathrm{~b}$ ). Cell dispersal and cell motility were confirmed by live cell imaging (Supplementary Movies: $A p c^{4 / 4} \mathrm{Cdhl}^{+/+} \operatorname{Lgr} 5 \mathrm{CreER} \mathrm{R}^{T 2} \mathrm{Adv}-$ Cre positive (Control Supplementary Movies 1. and 2.), $A p c^{A / /} \mathrm{Cdh}^{f / f l} \operatorname{Lgr} 5 \mathrm{CreER} \mathrm{R}^{T 2} \mathrm{Adv}-\mathrm{Cre}$ positive (experimental Supplementary Movie 3.), Figure 4a, Supplementary Figure S8). After 6 days, $>85 \%$ of the $A p c^{\Delta / A} C d h 1^{f /}$ ${ }^{A} \mathrm{Lgr}_{5 \mathrm{CreER}}{ }^{T 2} \mathrm{Ad}-\mathrm{Cre}-\mathrm{GFP}$ transfected structures displayed disrupted organoid structure with separated cells, compared

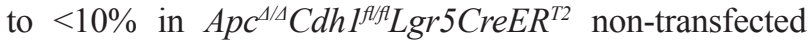
controls. Proliferation and apoptosis were quantified using EdU incorporation and cleaved caspase3 labelling, respectively. Reduced overall labelling of both markers were detected by 4-6 days after Ad-Cre-GFP transfection, although we cannot exclude apoptosis at earlier time-points (Supplementary Figure S9a,b). In cells with a ROSA26LSL-YFP reporter incorporated into the $A p c^{\Delta / A} C d h 1^{f /}$
${ }^{A}{ }_{\text {Lgr } 5 C r e E R}{ }^{T 2}$ line and transfected with Ad-Cre-GFP, an anti-GFP antibody labelled all cells. This suggested that the derived cells with associated mesenchymal phenotype and loss of E-cadherin were derived from intestinal epithelial cells (YFP or Ad-Cre-GFP positive, Supplementary Figure S10). As a crude control for loss of calcium mediated adhesion, EDTA exposure and culture in calcium free medium resulted in significantly different genotype independent phenotypes, with adenoma collapse, appearance of pyknotic nuclei within minutes to hours after calcium chelation, persistant labelling with CC3 and $\beta$-catenin and organoid fragmentation (Supplementary movie EDTA, Supplementary Figure S11). Importantly, no cells with a mesenchymal phenotype were observed following EDTA and low calcium media exposure.

As the disruption of adenoma organoid was mainly confined to the outer regions, we mapped the distribution of DAPI labelled cells into zones of $A p c^{\Delta / 4} C d h 1^{f /}$ ${ }^{A} L$ gr 5 CreER ${ }^{T 2}$ Ad-Cre-GFP organoids, and generated heat maps reporting localization of labelling (Figure 4c-f, Supplementary Figure S12). Outer zone cells with spindle morphology had increased labelling of nuclear $\beta$-catenin and also axin 2 , with cytoplasmic labelling of mesenchymal markers, fibronectin, vimentin and twist, consistent with $\beta$-catenin driven expression. As loss of E-cadherin labelling in $A p c^{4 / A} C d h 1^{f l f} L g r 5 C r e E R^{T 2}$ Ad-CreGFP cells was associated with the emergence of a cells with a high $\beta$-catenin labelling, these data supported the function of E-cadherin to decrease $\beta$-catenin. Moreover, the phenotypic transformation of epithelial cells to a mesenchymal morphology (EMT) was also associated with increased $\beta$-catenin nuclear localization.

\section{Cdh1 genetic complementation of intestinal adenoma in vitro}

In order to confirm that the phenotypes observed were directly attributable to $C d h 1$ loss of function, we performed genetic complementation. Co-infection of $A p c^{4 / A} C d h 1^{f / f} \operatorname{Lgr} 5 C r e E R^{T 2}$ adenoma cells with a CMV promoter driven adenovirus expressing either murine wild-type or an EC1 domain mutated Cdh1 cDNA, were combined in vectors with an IRES for the fluorescent reporter RFP (Ad-Cdh1-WT-RFP or Ad-Cdh1-MutRFP). The two mutations introduced into the EC1 domain were a tryptophan to alanine (W2A), involved in the strand swapping mechanism, and a mutation of the $\mathrm{Ca}^{2+}$ dependent binding site that introduces a bulky tryptophan into the binding site where there is normally a serine residue $(\mathrm{S} 78 \mathrm{~W})$. We first confirmed that these mutations led to complete loss of homophilic binding by expressing Ad-Cdh1-WT-RFP and Ad-Cdh1-MutRFP constructs in MCF7 cell controls (Supplementary Figure S13). Here, we utilised a murine E-cadherin-Fc domain protein to probe extra-cellular EC mediated binding function in a $\mathrm{Ca}^{2+}$ dependent manner using flow 
cytometry, and confirmed gain and loss of binding with Ad-Cdh1-WT-RFP and Ad-Cdh1-Mut-RFP, respectively. By co-infecting $A p c^{\Delta / \Delta} C d h 1^{\text {Al/f }} \operatorname{Lgr} 5 \mathrm{CreER}{ }^{T 2}$ adenoma cells with Ad-Cre-GFP combined with either Ad-Cdh1WT-RFP or Ad-Cdh1-Mut-RFP, we tested the effects of double transfection with Cre and Cdh1 expressing viruses. All single virus infection MOIs resulted in $>50 \%$ of cells expressing either GFP or RFP by 5-7 days, and both fluorescent reporters were detected following co-infection in proportionate expression ratios confirmed by imaging and flow cytometry (Supplementary Figure S13, Figure 5a,b).

Adenoviral transfection of $\mathrm{Apc}^{4 / \Delta} \mathrm{Cdhl}^{+/+} \mathrm{Lgr} 5 \mathrm{CreER} \mathrm{R}^{T 2}$ control organoids with Ad-Cre-GFP did not significantly change either the expression level of E-Cadherin or morphology, as expected (Figure 5a,b). Expression of Ad-Cdh1-WT-RFP and Ad-Cdh1-Mut-RFP did however increase overall E-cadherin labelling by flow cytometry, here using an anti-E-cadherin antibody to a C-terminal epitope, with frequent appearance of much smaller adenoma compared to adenoma that were not-infected (RFP negative) within the same culture (Figure 5a,c). In
$A p c^{4 / \Delta} C_{d h 1^{A l /} L g r 5 C r e E R^{T 2}}$ with Ad-Cre-GFP, decreased labelling for E-cadherin was observed as expected, and this was rescued by Ad-Cdh1-WT-RFP and Ad-Cdh1-Mut-RFP as judged by single channel flow cytometry (Figure $5 \mathrm{~b}$ ). On transfection of Ad-Cre in $A p c^{4 / \Delta} \mathrm{Cdhl}^{\mathrm{Alf} / \mathrm{Lgr} 5 \mathrm{CreER}} \mathrm{R}^{T 2}$ adenoma cells, loss of E-cadherin labelling was observed as before, and predominantly at the edge of adenomas, where separated rounded and elongated cells were visible (Figure 5a). Fluorescent labelling of cells and localisation using confocal imaging revealed an increase in overall $\beta$-catenin labelling in both the nucleus and cytoplasm in cells that had lost E-cadherin, and again with larger, separated, rounded and elongated cells (Figure 5e, top row). RFP labelled cells showed increased E-cadherin expression following either Cdh1-WT-RFP or Cdh1-MutRFP transfection as judged by flow cytometry, recovering overall levels to those of wild-type (Figure $5 \mathrm{~b}$ ). The morphology of the $A p c^{4 / 4} C_{d h 1^{+/+}} \operatorname{Lr} 5 C r e E R^{T 2}$ compared to the $A p c^{4 / A} C d h 1^{f l / f} L g r 5 C r e E R^{T 2}$ cells complemented with either Cdh1-WT-RFP or Cdh1-Mut-RFP, also differed.

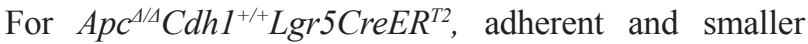
cells occurred in Ad-Cre-GFP and Cdh1-WT-RFP double-
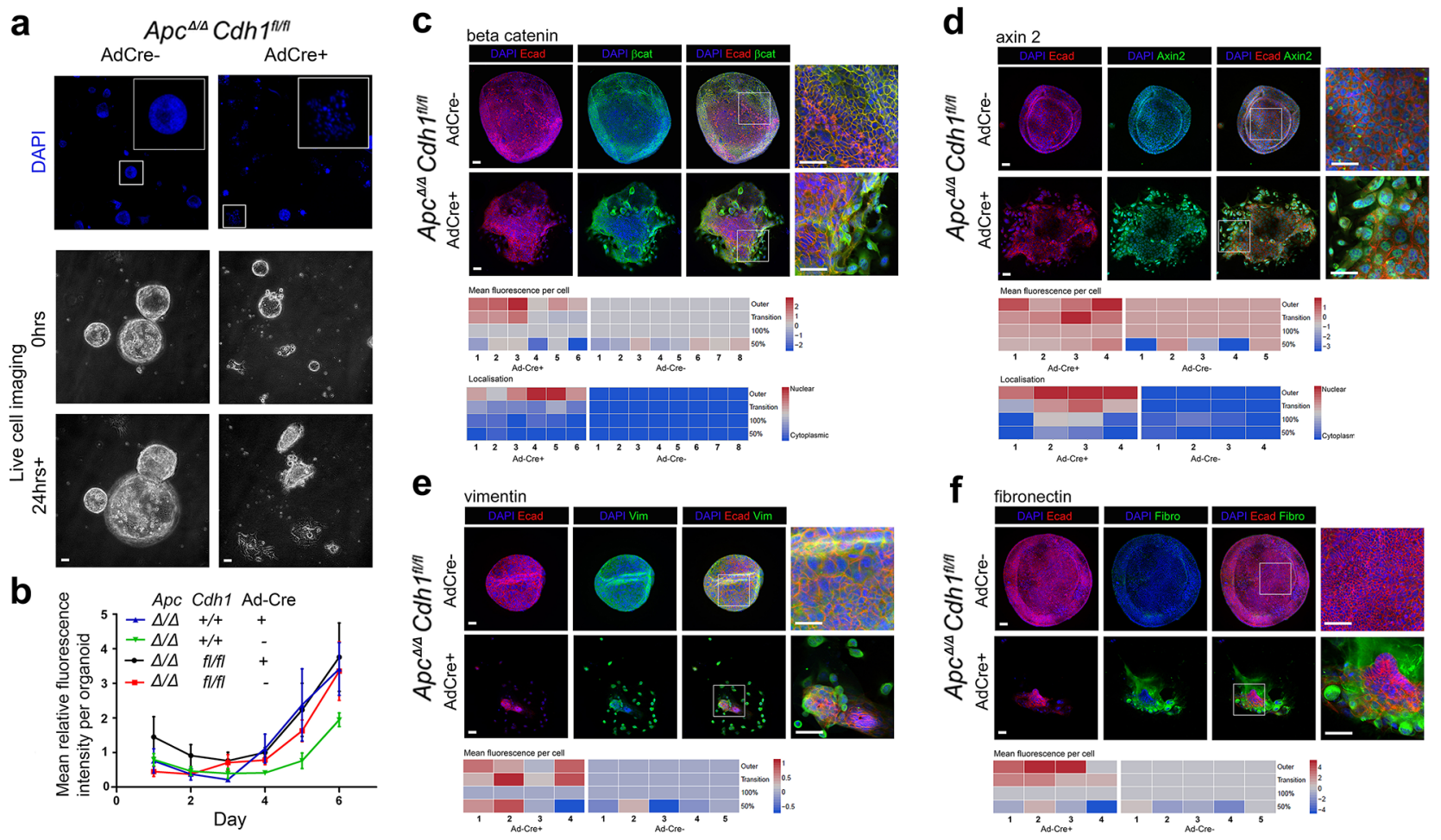

Figure 4: Adenovirus-Cre expression in $A p c^{4 / \Delta} C_{d h 1^{f / f}}$ intestinal adenoma organoids induces floxed $C d h 1^{4 / \Delta}$ alleles, adenoma disruption and a mesenchymal phenotype. a. Ad-Cre-GFP treatment of $A p c^{\Delta / A} C d h 1^{f / f}$ adenoma organoids, labeled with DAPI, and frames from live cell imaging (baseline and after 24 hours; see Supplementary movies). $A p c^{A / A} C d h l^{A / A} \mathrm{Ad}-\mathrm{Cre}-\mathrm{GFP}$ organoids show a fragmented appearance at low power, four days following Ad-Cre-GFP transfection and culture. Scale bars $100 \mu \mathrm{m}$. b. Growth of adenoma organoids quantified with total DAPI fluorescence ( $>10$ intact adenoma per time-point). No significant genotype differences in organoid growth were observed. c-f. Labeling of $A p c^{1 / 4} C d h 1^{f / f}$ adenoma regions and cellular localization following Ad-Cre-GFP transfection for (c) $\beta$-catenin, (d) axin2, (e) vimentin and (f) fibronectin, displayed as heatmaps (fluorescence signal $\log _{2}$ transformed, see Methods and Supplementary Figure S12). Note outer organoid localization of vimentin and fibronectin, with $\beta$-catenin and axin2 nuclear labeling. Scale bars $50 \mu \mathrm{m}$. 
labelled cells (yellow) (Figure 5c). In contrast, generally isolated and non-adherent cells occurred in Ad-Cre-GFP and Cdh1-Mut-RFP double-labelled cells (yellow), (Figure $5 \mathrm{a}$,e bottom row). Re-expression of Cdh1-WT-RFP in Ad-Cre-GFP transfected $A p c^{1 / 4} \mathrm{Cdh}^{1 / 1 / 4} \mathrm{Lgr} 5 \mathrm{CreER}^{T 2}$ cells appeared to result in expression of E-cadherin (Figure 5e middle row, left panel), clear membrane-bound $\beta$-catenin labelling, and adhesive and less rounded and flattened morphology (Figure 5e, middle row, right panel, arrows), For Cdh1-Mut-RFP co-infected $\mathrm{Ap} c^{1 / 4} \mathrm{Cdh}^{\nexists f / f} \mathrm{Lgr}^{\mathrm{CCreER}} \mathrm{R}^{T 2}$ cells, $\beta$-catenin labelling remained high and appeared cytoplasmic and nuclear with cells appearing rounded and non-adherent (Figure 5e, lower row, left and right panels, arrowheads). a
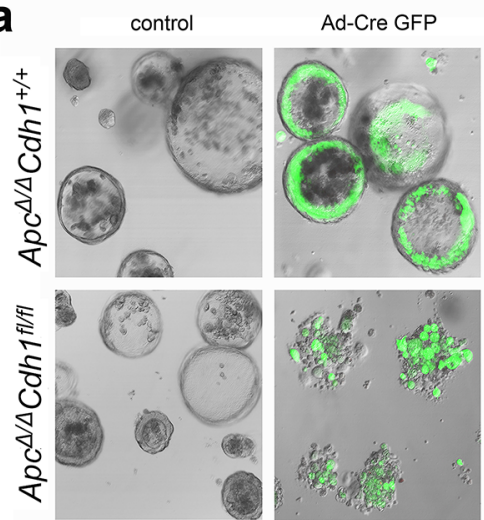

b
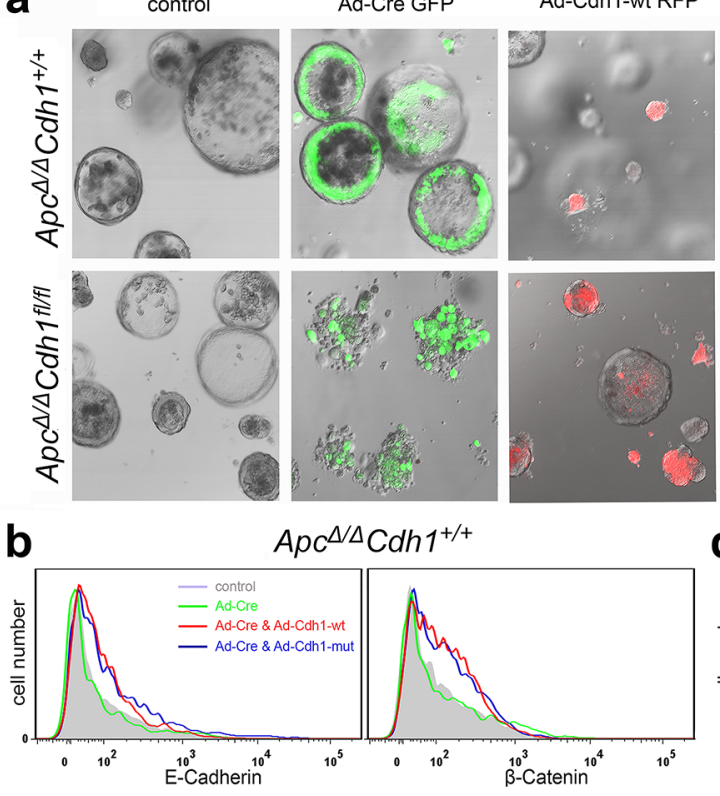

d
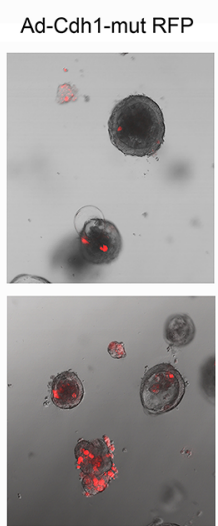

\section{d}
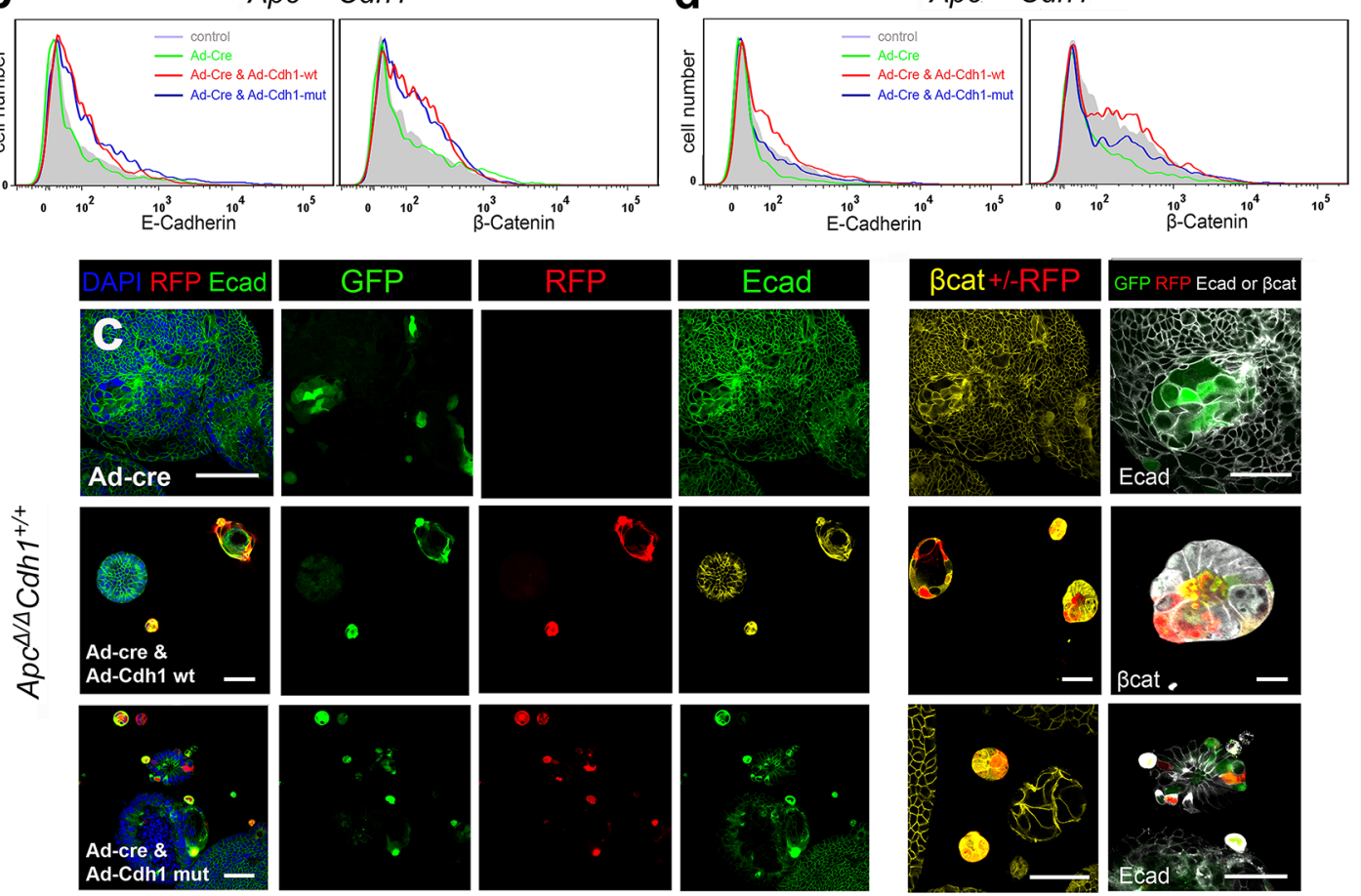
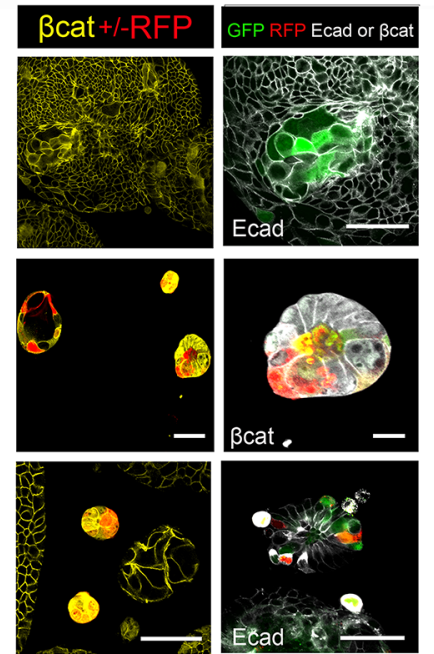

Figure 5: Genetic complementation of $A p c^{1 / 4} C_{d h} I^{f / f}$ adenoma organoid cells with adenovirus either expressing wild-type or EC1 domain mutants of $\boldsymbol{C d h}$. a. Adenovirus transfection of $A p c^{1 / A} C d h 1^{+/ /}$and $A p c^{1 / A} C d h 1^{A / /}$ intestinal adenoma organoids with AdCre-GFP, Ad-Cdh1-WT-RFP and Ad-Cdh1-Mut-RFP. Ad-Cre-GFP is expressed in the outer cells of the $A p c^{1 / 4} C d h 1^{+/+}$control organoid, and in cells of the disrupted organoid in $A p c^{1 / A} C d h 1^{\nexists f / A}$. Expression of either Ad-Cdh1-WT-RFP or Ad-Cdh1-Mut-RFP results in small contracted organoids in both genotypes. Complementation of $A p c^{4 / A} C d h h^{f f f} \mathrm{Ad}$-Cre-GFP with Ad-Cdh1-WT-RFP, results in adherent double expressing (yellow) cells in both genotypes. For complementation with Ad-Cdh1-Mut-RFP, double expressing cells (yellow) appear less adherent and separate. $\mathbf{b} \& \mathbf{d}$. Flow cytometry profiles of E-cadherin and $\beta$-catenin antibody binding to $A p c^{1 / 4} C d h 1^{+/+}$adenoma organoid cells with adenoviral transfection. With Ad-Cre-GFP alone, there was no effect on overall E-cadherin and $\beta$-catenin expression, but when combined with either Ad-Cdh1-WT-RFP or Ad-Cdh1-Mut-RFP, results in increased E-cadherin and $\beta$-catenin. In $A p c^{\Delta / A} C d h 1^{\nexists f /}$ cells, loss of E-cadherin and $\beta$-catenin occurs following Ad-Cre-GFP transfection, and is rescued by either Ad-Cdh1-WT-RFP or Ad-Cdh1-Mut-RFP. (c) In $A p c^{\Lambda / A} \mathrm{Cdh}^{++/}$, infection with Ad-Cre-GFP does not result in E-cadherin loss (top row), and Ad-Cdh1-WT-RFP (middle row) or Ad-Cdh1-Mut-RFP (bottom row) expression results in contracted organoids as in a. Note that $\beta$-catenin appears cytoplasmic and membrane bound. (Continued) 

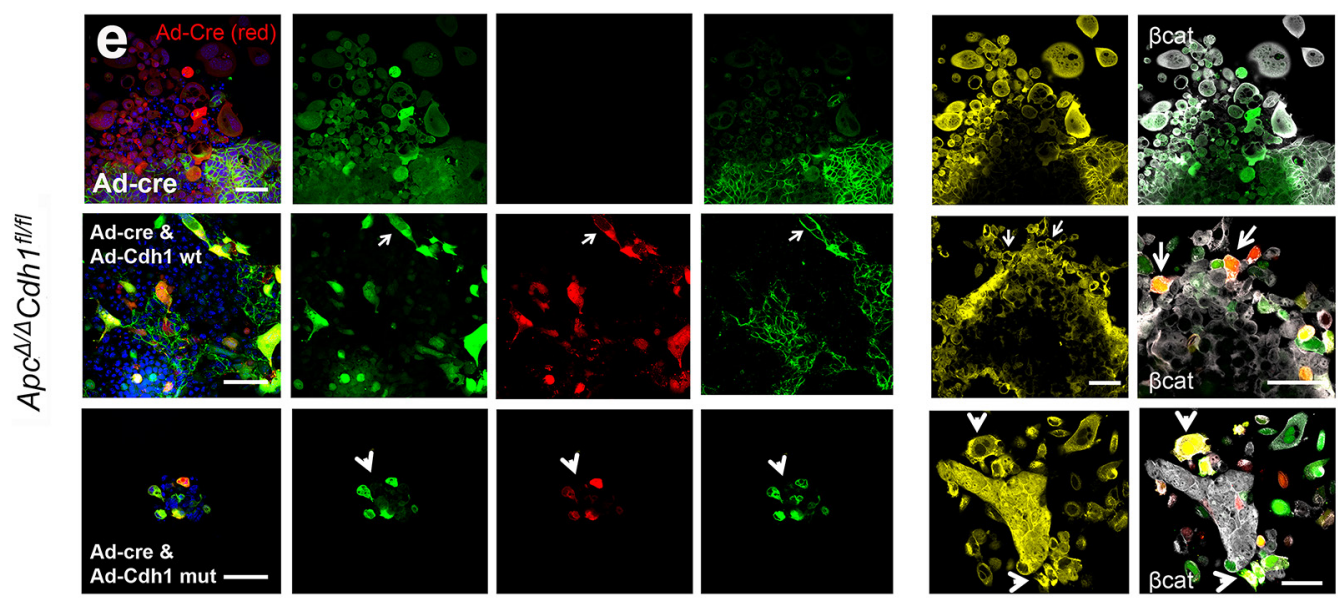

Figure 5: (Continued) Genetic complementation of $A p c^{\Delta / A} C d h 1^{f l / t}$ adenoma organoid cells with adenovirus either expressing wild-type or EC1 domain mutants of $\boldsymbol{C d h 1}$. e. In $A p c^{\Delta / A} C d h 1^{A / f t}$ (top row) Ad-Cre-GFP transfection results in loss of E-cadherin, cytoplasmic and nuclear localisation of $\beta$-catenin, and disrupted organoid morphology (large, separate, rounded or elongated) as in a. Complementation of $A p c^{\Delta / A} C d h 1^{f / f}$ is shown in two example panels. For Ad-Cre-GFP with Ad-Cdh1-WT-RFP (middle row), results in adherent double expressing (yellow) cells, associated with expression of E-cadherin (arrows, left panel) and predominantly membrane bound $\beta$-catenin (arrows, right panel). For complementation with Ad-Cdh1-Mut-RFP (yellow cells, bottom row, left panel), this results predominantly in non-adherent cells, with mainly cytoplasmic and nuclear $\beta$-catenin expression (white arrow heads, right panel). Scale bar $100 \mu \mathrm{m}$ in (a), otherwise $50 \mu \mathrm{m}(\mathrm{c}, \mathrm{e})$.

As the relatively small proportion of cells doubly transfected precluded additional quantitative assessment of bulk gene expression studies and western blots, we utilized imaging flow cytometry (ImageStream) to attempt to quantify the intra-cellular localization of $\beta$-catenin following complementation (Supplementary Figure S14 Figure 6a-d). We first validated differential $\beta$-catenin localization using imaging flow cytometry with both MCF7 (cytoplasmic $\beta$-catenin) and Colo201 (nuclear $\beta$-catenin) control cells, and we were able to quantify relative nuclear and cytoplasmic localization, including example images and the more accurate similarity dilate plots (Figure 6a,b). In $\mathrm{Apc}^{4 / 4} \mathrm{Cdh}^{+/+} \mathrm{Lgr} \mathrm{CreER}{ }^{T 2}$ control cell suspensions, no significant redistribution of $\beta$-catenin appears following Ad-Cre-GFP, Cdh1-WT-RFP and Cdh1-Mut-RFP expression (Figure 6b,c,d, left panels). In $A p c^{A / A} C d h 1^{A f / A} \operatorname{Lgr} 5 \mathrm{CreER} R^{T 2}$ however, expression of Ad-Cre-GFP resulted in detectable increase in nuclear $\beta$-catenin labelling compared to non-Cre expressing controls (Supplementary Figure S14, Figure 6b,c,d, right panels). When Ad-Cdh-WT-RFP was also co-expressed, a statistically significant reduction in the proportion of cells with nuclear $\beta$-catenin was observed with the similarity dilate function, compatible with a partial rescue and the fluorescent localization by confocal microscopy (Figure 5b,c,d). For Cdh1-Mut-RFP, the effect appeared reversed, with even higher overall cytoplasmic and nuclear $\beta$-catenin labelling in the nucleus in expressing cells, again reflecting the fluorescent imaging (Figure 6b,c,d). All of the quantitative cell data from two separate experiments are shown and statistically analysed for nuclear $\beta$-catenin localization using image stream (Figure 6d). Analysis of these data support the function for the cytoplasmic domain of E-cadherin as a negative regulator of nuclear $\beta$-catenin, but this only appears optimal in reversing the loss of function of E-cadherin when the EC1 domain dependent adhesion function remains intact (Ad-Cdh-WT-RFP). We interpret these observations in relation to the effectiveness of the sequestration of $\beta$-catenin, as this may optimally occur in the stable membrane located adhesion complex. Importantly, Ad-Cre-GFP and Cdh1-Mut-RFP double transfected cells still appeared to retain separate nonadherent cells by confocal imaging, some with rounded and flattened cells, also associated with higher levels of nuclear $\beta$-catenin. Using Imagestream, Cdh1-Mut-RFP rescued cells also had much higher nuclear $\beta$-catenin (Figure 6d), suggesting that $\beta$-catenin binding to the cytoplasmic domain of E-cadherin alone is not sufficient to confer complete reversal of the $C d h 1$ loss of function phenotype, further implicating the $\mathrm{EC} 1$ binding domain as an important component of the E-cadherin mediated negative regulation of the adhesion and EMT phenotype.

\section{DISCUSSION}

\section{Cdh1 is essential for embryonic development}

E-cadherin is an essential protein, as $C d h 1^{-1}$ is known to be embryonic lethal in the mouse because of trophectoderm failure by E2.5-E3.5 [37]. Expression of Cre driven by the promoter of villin (Vil-Cre), is active in the visceral endoderm from E9 [28], suggesting that $C d h 1^{f t / f}$ recombined using Vil-Cre might be expected to bypass the post-implantation developmental defect [29]. 

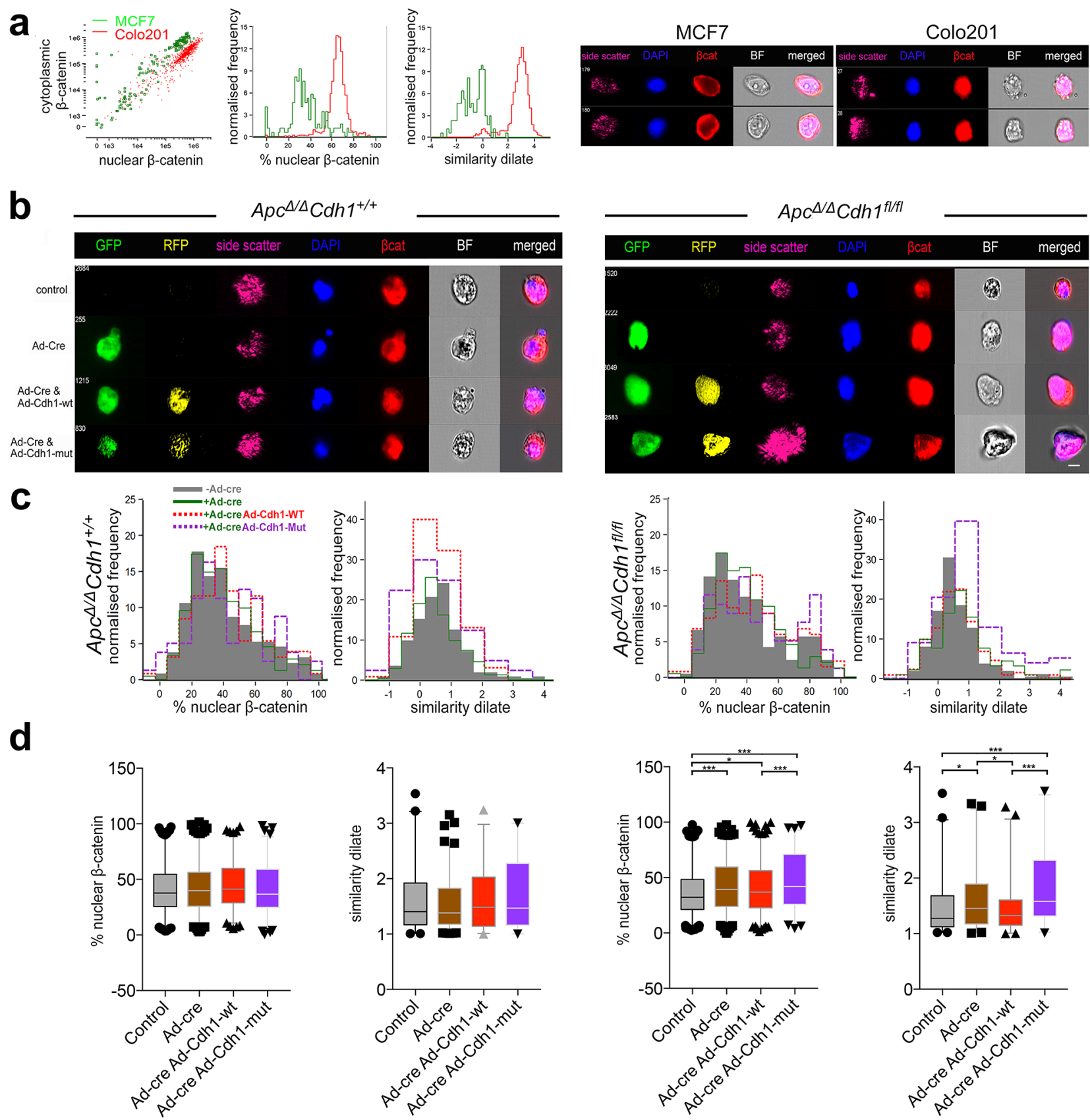

Figure 6: Localization of nuclear $\beta$-catenin in $\mathrm{Apc}^{4 / \Delta} \mathrm{Cdh}^{\mathrm{At/l}}$ adenoma organoids following complementation with adenovirus expressing wild-type and EC1 domain mutant of $\boldsymbol{C d h}$ 1. a. Validation of image stream analysis of $\beta$-catenin localization in MCF7 and Colo201 cells with cytoplasmic and nuclear $\beta$-catenin localization, respectively. Note difference in the $\%$ of nuclear $\beta$-catenin and similarity dilate between the cell lines, with MCF being cytoplasmic and Colo201 being nuclear. Image stream representative images displaying differential $\beta$-catenin localization in the cell lines. b. Image stream representative images displaying differential $\beta$-catenin localization in the adenoma organoid cells with respect to genotype. $\mathbf{c}$. Image stream evaluation for nuclear $\beta$-catenin utilises either a DAPI mask (left graph, \% nuclear $\beta$-catenin) or similarity dilate (right graph, direct comparison of DAPI with $\beta$-catenin). Shown are the profiles of nuclear vs. cytoplasmic $\beta$-catenin localization for non-Ad-Cre-GFP transfected (grey shading) versus Ad-Cre-GFP (green), with either Ad-Cdh1-WT-RFP (red) or Ad-Cdh1-Mut (purple) co- transfected adenoma organoids. d. Quantification (mean and $95 \%$ confidence interval with outliers) and statistical analysis of the $\%$ nuclear $\beta$-catenin and similarity dilate (R12 region, Supplementary Figure S14) with respect to genotype and intervention. Note the rescue of the increase of nuclear $\beta$-catenin localization in double Ad-CreGFP and Ad-Cdh1-WT-RFP transfected $A p c^{4 / A} C d h l^{A f / f}$ cells, and the significant overall increase in nuclear $\beta$-catenin localization following Ad-Cdh1-Mut (see also Supplementary Figure S14). ${ }^{*} \mathrm{p}<0.05,{ }^{* *} \mathrm{p}<0.01,{ }^{* * *} \mathrm{p}<0.001$, one-way ANOVA, one tailed t-test. Scale bar $8 \mu \mathrm{m}$. 


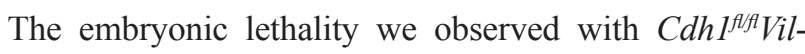
Cre was, however, also associated with defects in extraembryonic development. The alternative Vil-Cre transgene (TgVil-cre-997Gum) that uses a $12.4 \mathrm{~kb}$ fragment of the villin gene promoter, is also active in the intestine from E14.5 but not the yolk sac, and has been previously reported in combination with $C d h 1^{f l f l}$ [38]. Here it to resulted in lethality, but in the early post-natal period, meaning that conditional and tissue specific Cre activation was required to evaluate $C d h 1^{f l f t}$ in the adult mouse intestine [29, 39].

\section{Cdh1 and Apc combined to generate additive intestinal phenotypes and $\beta$-catenin nuclear localization}

When we combined conditional alleles of $C d h 1^{\text {flft }}$ with $A p c^{A / f l}$ and tamoxifen-inducible intestinal specific Cre transgene (Vil-CreER ${ }^{T 2}$ ), we observed rapid and lethal intestinal phenotypes with marked nuclear localization of $\beta$-catenin in intestinal cells $[24,29,40]$. Cdh $1^{\text {fl/fl }}$ recombination alone resulted in lethality due to disrupted intestinal barrier function, with increased crypt cellular proliferation and intact E-cadherin in some cells suggested a regenerative response. In keeping with regeneration, increased expression of the EGF receptor and the EGF ligand amphiregulin (Areg) were observed, consistent with crypt myo-fibroblast mediated expression of Areg, and the Areg requirement in post-irradiation intestinal regeneration [41]. The altered localization of secretory cell lineages, in particular Paneth cells within villi, and the abundance of goblet and entero-endocrine cells, may also have been secondary events to the defects in adherence and regenerative function, as reported previously [40]. These findings are consistent with similar intestinal phenotypes following disruption of other components of the adherens complex, in particular p120, EphB3 and ADAM10 [9, 42, 43].

Our most striking result was, however, the increased nuclear $\beta$-catenin localization that appeared in intestinal cells when disruption of $A p c$ and $C d h 1$ were combined, and the correlation with increased Wnt target gene expression including CD44 and $c-M y c$. As EphB signalling can also be mediated by $A D A M 10$ cleavage of E-cadherin, and whilst $E p h B 2$ and $E p h B 3$ are also Wnt target genes, the significantly increased $E p h B 3$ expression in the setting of $C d h 1$ loss may have been independent of Wnt signalling [44]. Whilst these genes can be up-regulated in inflammation and regeneration, the direct effects of $\beta$-catenin do appear more likely to be the driver in this context [45]. With respect to the observation relating to the paradoxical suppression of Axin2, this suggests that the Axin 2 may be reduced due to loss of E-cadherin. It is plausible that this may also be an indirect mechanism via inflammatory and regeneration mediated transcriptional suppression of the Axin2 promoter. Moreover, in support of this hypothesis, Notch signalling also regulates intestinal secretary cell differentiation and regeneration, and can indirectly suppress Axin2 expression to modify $\beta$-catenin supply $[46,47]$. The data obtained in this conditional mouse model also have relevance for intestinal inflammatory disease, as chromosome 16q22, which contains $C D H 1$, has been identified as a susceptibility locus for ulcerative colitis in a large genome-wide association study [48], as well as in colorectal cancer (see below) $[26,27]$. The lack of association in a subsequent GWAS meta-analysis for Crohn's disease, is countered by a specific risk haplotype that had increased cytoplasmic E-cadherin expression due to a truncated protein, supporting the functional role of E-cadherin as a modifier of human inflammatory intestinal disease [49].

\section{E-cadherin inhibits nuclear $\beta$-catenin localization in the context of Apc dependent adenoma organoids}

Surprisingly, conditional generation of intestinal adenoma following tamoxifen administration in $A p c^{f /}$ ${ }^{A f} \mathrm{Cdh}^{\mathrm{Alf} / \mathrm{Lgr}} 5 \mathrm{CreER}{ }^{T 2}$ did not result in frequent and detectable recombined $\mathrm{Cdh}^{\Delta / \Delta}$ alleles, yet subsequent adenoma organoid cell culture manipulated using adenovirus Cre vectors, induced recombination of Cdh1 alleles. The observed EMT phenotype and $\beta$-catenin nuclear localization subsequently observed, also strongly support E-cadherin as an inhibitor of $\beta$-catenin activated Wnt signalling, mirroring the $\beta$-catenin up-regulation in the intestinal crypt-villous units. The cell EMT phenotype was rescued in cells complemented by expression of wildtype E-cadherin, in terms of adhesion and cell shape, but not by an EC1 extra-cellular domain E-cadherin mutant that lacked homophilic binding. These data do not exclude other regulators of EMT, including those related to the activation of $\beta$-catenin and compensation for E-cadherin depletion, that may have not been reversed by $C d h 1$ complementation. For example, multiple levels of regulation exist to decrease E-cadherin expression such as transcriptional repressors of $C d h 1 \mathrm{mRNA}$, including slug, snail, twist, and ZEB-1, but these also modify other pathways [50-55]. Activation of these pathways following E-cadherin loss of function may also account for the apparent reduction in proliferation and apoptosis detected in remaining E-cadherin null cell populations 4-6 days after recombination. It therefore remains unknown whether there exists heterogeneity in the cellular response to the loss of E-cadherin, and this partly may be determined by cellular context. In the evaluation of potential EMT pathways in intestinal adenoma and organoids, $C d h 1$ was

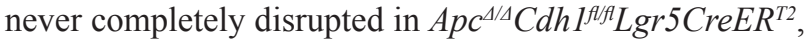
and so this limited the potential value of a specific transcriptomic analysis to identify these signals [30]. Importantly, these data also suggest that E-cadherin tumor suppressor function may not act through the cytoplasmic domain- $\beta$-catenin binding alone, but may also require EC1 
domain binding in trans and subsequent stable adhesion complex formation. One hypothesis is that cells with complete loss of Cdh1 may have not survived in vivo, as Cdh1 $1^{\text {flflf } V i l-C r e E R^{T 2}}$ also showed increased caspase mediated apoptosis and detachment, similar to the reports of E-cadherin loss being involved in the onset of anoikis [56]. Subsequent and on going, experiments will need to carefully evaluate the temporal cellular events, including gene expression, that follow $C d h 1$ loss of function in vitro in intestinal organoids with $A p c^{\Delta / 4}$, as in this case. Importantly, $C d h 1$ cell autonomous function also needs to be evaluated in the context of intact $A p c$ using stem cell derived intestinal organoids and conditional alleles, where it is still possible adhesion and EMT phenotypes may also arise in specific contexts.

Other experimental evidence supports our observations for the functional role of E-cadherin as an inhibitor of $\beta$-catenin. In Caenorhabditis elegans, there appear distinct $\beta$-catenin homologues for adhesion and signalling functions $[11,57]$ and in Xenopus laevis embryos, over-expression of cadherins results in reduced dorsal axial structures identical to that seen with depletion of maternal $\beta$-catenin [58]. In Drosophila melanogaster, either a wild-type E-cadherin (shotgun) or a dominantnegative truncated form (lacking the extra-cellular domain) were capable of titrating armadillo ( $\beta$-catenin) between a signalling and adherens junction pools, and over-expression of both constructs resulted in phenotypes similar to either wingless or armadillo mutants [59]. In mammalian cells, over-expression of E-cadherin can suppress cell proliferation via negative regulation of $\beta$-catenin [60], independent of the adhesive function of E-cadherin in some instances [61]. Similarly, siRNA knock-down of E-cadherin can result in increased nuclear $\beta$-catenin expression and a $\beta$-catenin/Tcf4 TOP-FLASH reporter [62]. In the Rip1Tag2 model of $\beta$-islet cell carcinogenesis, however, the transition from adenoma to carcinoma appeared stimulated by dominant-negative E-cadherin expression [63]. Moreover, $\beta$-catenin dependent Wnt regulation by E-cadherin was observed in a derived cell line, yet expression of a stable mutant of $\beta$-catenin did not promote the same tumour phenotypes [64]. Recently, expression of conditional, mutated and stabilised $\beta$-catenin in the mouse failed to generate a significant colonic adenoma phenotype unless combined with a $C d h 1$ heterozygote allele, suggesting that the adhesion complex sequestration of mutated $\beta$-catenin limited its nuclear translocation [25]. Direct functional effect of $\mathrm{CDH1}$ germ-line nonsense and missense mutations increases risk of Hereditary Diffuse Gastric Cancer (HDGC), and in some instances to lobular breast cancer $[65,66]$. The localization of $C D H 1$ mutations to both extra-cellular and intra-cellular E-cadherin domains confers invasive properties, and is consistent with a dependency on an intact adhesion complex [67]. These data in combination with that presented in this paper further highlight the importance of the functional potential of the recently rs9929218 polymorphism in colorectal cancer susceptibility and prognosis [26, 27].

In summary, these findings have mechanistic implications for human cancers with co-existing $A P C$ and $\mathrm{CDH} 1$ loss of function, as the enhanced $\beta$-catenin function and invasive phenotypes that arise point to the important tumour suppressor function of both the protein binding functions of intact E-cadherin.

\section{MATERIALS AND METHODS}

\section{Mice}

Animal work was performed under a UK Home Office licence, and approved by University of Oxford ethics committee. The mouse lines were: $C d h 1^{+/-}(\mathrm{C} 57 \mathrm{~B} 16 \mathrm{~J} /$ B6D2), $A p c^{\text {Min }}$ called 'line1' [31], backcrossed $>10$ generations onto C57BL/6J. Apc $c^{A l / l}\left(A p c^{\text {tmlTno }}\right)[68], C d h 1^{A l}$ ${ }^{A l}\left(C_{d h} 1^{\text {tmlJjon }}\right)$ [69], RosaYFP ${ }^{\text {fllfl }}$ (Gt(ROSA)26Sor ${ }^{\text {tm1(EYFP) }}$ $\left.{ }^{\mathrm{Cos}}\right)$ [70], Vil-Cre (Tg(Vil-cre) and Vil-CreER ${ }^{T 2}$ (Tg(Vil-cre/

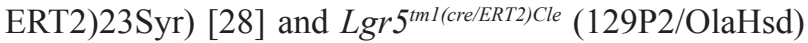
were also backcrossed to $\mathrm{C} 57 \mathrm{Bl} / 6 \mathrm{~J}$ [14]. Vil-Cre is active from embryonic day 10. Vil-CreER ${ }^{T 2}$ is activated with exogenous tamoxifen. Genotyping PCRs were performed as reported, briefly ( $5^{\prime}-3$ ', forward-F and reverse-R): $A p c$ F GTTCTGTATCATGGAAAGATAGGTGGTC and RCA CTCAAAACGCTTTTGAGGGTTG (GAGTACGGGG TCTCTGTCTCAGTGAA for recombined product), Cdhl F CCCCAAACTCGTTGATTGAT and R CCATAC ACTGATAATGTCAGA (CCTGCCATGATTGTCATG GAC for recombined product). Genotype combinations were generated by experimental breeding. Embryos were staged by taking mid-day on the day of seminal plug detection as embryonic day 0.5 (E0.5). Weighed embryos were fixed in $4 \%$ neutral buffered formalin.

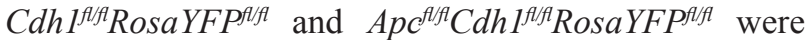
crossed with either Vil-CreER ${ }^{T 2}$ or Lgr5CreER ${ }^{T 2}$ mice, and then inter-crossed to generate $C d h 1^{f l f} R o s a Y F P^{f l l f l} V i l$ -

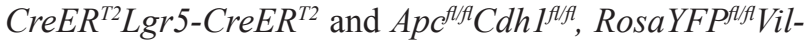
CreER ${ }^{T 2}$ Lgr5-CreER $R^{T 2}$ animals. Apc ${ }^{A l f l} \mathrm{Cdh}^{+/+}$RosaYFP ${ }^{f /}$ ${ }^{A} \mathrm{Vil}_{\text {-CreER }}{ }^{T 2} / \mathrm{Lgr} 5-C r e E R^{T 2}$ animals were used as controls. Serial weights were compared using an ANOVA with Bonferroni post-test for each time point. Mendelian ratio analysis utilised the $\chi^{2}$ test, and other comparisons between genotypes were made using student's t-test or one-way ANOVA. All p-values were two-sided.

\section{Conditional cre activation}

For Vil-CreER ${ }^{T 2}$ activation (age 8-12 weeks), 40 mg. $\mathrm{kg}^{-1}$ tamoxifen in corn oil was administered by intraperitoneal injection on five sequential days (low dose tamoxifen) or $200 \mathrm{mg} \cdot \mathrm{kg}^{-1}$ on two sequential days (high dose tamoxifen). Wild-type controls were also injected to ensure the observed effects were not attributable to the 
tamoxifen. High dose tamoxifen with Apc ${ }^{\text {flfl }} \mathrm{Lgr}_{5} \mathrm{CreER}^{T 2}+$ resulted in adenoma formation between 30 and 80 days. Mice were monitored to a defined humane endpoint (scoring system based on sequential assessments of body condition, weight, respiratory rate, evoked response and tumour/intestinal features) at which time they and matched control animals were sacrificed. Intestinal or splenic samples for RNA extraction were snap frozen or collected in RNAlater ${ }^{\circledR}$ (Ambion). Cre recombinase activation was detected using the Rosa-YFP reporter and tissue genotyping for recombined $A p c$ and $C d h 1$ alleles.

\section{BrdU and EdU labelling}

For BrdU, administration of a single intra-peritoneal injection of $100 \mathrm{mg} . \mathrm{kg}^{-1}$ (Roche, UK) was either $2 \mathrm{hr}$ or 24 $\mathrm{hr}$ before dissection, with $\geq 2$ animals of each genotype for each time point. Immuno-labelling used a nuclease based anti-BrdU labelling and detection kit (Roche, UK) at $4{ }^{\circ} \mathrm{C}$ in a humidified chamber, followed by incubation with anti-mouse-Ig-fluorescein (dilution 1:10) for 2 $\mathrm{hr}$ at $4^{\circ} \mathrm{C}$. The cumulative frequency of BrdU positive nuclei counted from the crypt base to the villus tip was quantified for at least 40 crypt-villus units per animal. To assay proliferation in vitro, adenoma cultures (see below) were labelled with the thymidine analogue 5-ethynyl-2'deoxyuridine $(10 \mu \mathrm{M}, \mathrm{EdU})$ using Click-iT® EdU Alexa Fluor ${ }^{\circledR} 55$ (Invitrogen, UK).

\section{Quantitative RT-PCR}

RNA was isolated from intestinal samples using TRI reagent (Applied Biosystems, UK). Contaminant genomic DNA was removed using the TURBO DNA-free kit (Applied Biosystems, UK). cDNA was synthesized from $1.5 \mu \mathrm{g}$ of total RNA using the High Capacity cDNA Reverse Transcription Kit (Applied Biosystems, UK). Real-time PCR (RT-PCR) analysis was performed with a Rotor Gene Q PCR cycler (Qiagen, UK). Standard curves were performed with serial dilutions of cDNA. Experiments were performed in duplicate and expression levels were normalized to $\beta$-actin and Hprt expression levels using the $\Delta \Delta \mathrm{Ct}$ method. Reference genes were selected using Genorm ${ }^{\text {PLUS }}$ [71]. Primer sequences used to amplify cDNA fragments in Supplementary Methods (Supplementary Table S1).

\section{Expression microarray}

RNA was extracted using an RNeasy kit (Qiagen) from small intestine samples taken from 8-14 weekold mice and stored in RNAlater (Sigma) at $-80^{\circ} \mathrm{C}$. Samples were obtained 4-5 days after injection of tamoxifen to induce the following conditional genotypes $\left(A p c^{+/+} C_{d h 1^{+/+}}, A p c^{f / f l} C d h 1^{+/+}, A p c^{+/+} C d h 1^{f l f l}\right.$ and $A p c^{f / /}$ $\left.{ }^{f l} C d h 1^{f l f t}\right)$. RNA was hybridized to Illumina Mouse
Whole Genome 6 v2 BeadChips (Illumina, San Diego, CA, Wellcome Trust Centre for Human Genetics, Oxford, UK). Data manipulation and analysis were performed using R3.1.1 (R Development Core Team, 2015), with microarray-specific packages obtained from the Bioconductor repository (Bioconductor 3.0). Raw data were normalized with 'lumi' [72] and Significance Analysis of Microarrays [73] was with 'siggenes'. Mapping of Illumina identifiers to annotation terms was done with 'biomaRt' and data from the Ensembl BioMart database (European Bioinformatics Institute, Cambridge, UK). Gene Set Enrichment analysis was with GSEA 2.0.14 (Broad Institute).

\section{Fluorescence confocal imaging and analysis}

Tissue samples were fixed in $4 \%(\mathrm{v} / \mathrm{v})$ neutral buffered formalin at RT for $24 \mathrm{hr}$, before dehydration and paraffin embedding. Sections $(5 \mu \mathrm{m})$ were processed by standard techniques. Briefly, slides were de-waxed in xylene, rehydrated followed by antigen de-masking in sodium citrate buffer (10 mM, pH6.0) in a pressure cooker for $2 \mathrm{~min}$ at $125^{\circ} \mathrm{C}$ and $10 \mathrm{~min}$ at $85^{\circ} \mathrm{C}$. Washed tissue sections (Tris-buffered saline, TBS, $\mathrm{pH} 7.4$ ) were blocked in $10 \%$ goat serum/ Tween $20^{\circ} 0.5 \%(\mathrm{v} / \mathrm{v})$ for $1 \mathrm{hr}$ at RT followed by incubation with primary antibodies; Axin 2 (rabbit, 1:100, ab32197, Abcam, UK); $\beta$-catenin (mouse, 1:200, BD610154, BD laboratories, UK); Chromogranin A (rabbit, 1:300, 1773-1, Epitomics, USA); Cleaved Caspase 3 (rabbit, 1:200, \#9664, Cell Signaling, UK); c-Myc (rabbit, 1:200, \#sc-764, Santa Cruz, USA); E-cadherin (mouse, 1:200, BD610182, BD laboratories, UK); EphB2 (goat, 1:200, \#AF467, R\&D, UK); GFP (chicken, 1:500, ab13970, Abcam, UK); Cre (mouse, 1:500, \# 3120, Millipore, UK); Ki-67 (rabbit, 1:300, RM9106, Thermo Scientific, USA); Lysozyme (rabbit, 1:500, A0099, Dako, Denmark); Mucin 2 (rabbit, 1:500, sc-15334, Santa Cruz, USA) and Villin (mouse, 1:50, sc-58897, Santa Cruz, USA) at $4^{\circ} \mathrm{C}$ overnight. After 3 washes in TBS tissue sections were incubated with secondary fluorescentconjugated antibodies (goat anti-mouse or goat anti-rabbit, Alexa-488, -555, -594, or -647, 1:300, Invitrogen, USA, or goat anti-chicken dylight-550, Abcam, UK) for $2 \mathrm{hr}$ at RT or biotinylated antibodies as per manufacturer's instructions (Vectastain elite avidin-biotin complex kit, Vector Laboratories). After washing, fluorescent-labeled tissue sections were counterstained with DAPI (1:5000, D9663, Invitrogen, USA) and mounted with Prolong gold anti-fade reagent (P36930, Invitrogen, USA). Fluorescent images were acquired using a confocal microscope Olympus Fluoview FV1000. Sections labeled using a biotinylated secondary antibody were counterstained with haematoxylin, dehydrated through an alcohol series and mounted with Depex mounting medium (Electron Microscopy Sciences, USA). Images of H\&E sections were acquired with an Olympus microscope BX60 with 
a Nuance CCD system. For adenoma, fixation was in $4 \%(\mathrm{v} / \mathrm{v})$ paraformaldehyde in PBS 10 mins at RT that also resulted in dissolution of matrigel. Each sample was washed in PBS three times, blocked (1 hr) with 10\% serum (same source as secondary antibody, Vector laboratories), $0.5 \%$ Triton $\mathrm{x} 100$ in TBS (v/v). Samples were incubated with the primary antibody (vimentin (rabbit, 1:200, ab35939, Abcam, UK), twist (rabbit, 1:200, ab49254, Abcam, UK), fibronectin (rabbit, 1:200, ab23750, Abcam, UK) in $3 \%$ serum, $0.3 \%$ triton and TBS, following 18 $24 \mathrm{hr}$ washed in TBS (3x 3 minutes) and incubated with secondary antibody in TBS for 2 hours as above.

The position of Paneth cells (identified by positive lysozyme immuno-labelling) for different genotypes and the distance from the crypt base to a given cell was measured in $\mu \mathrm{m}$ using ImageJ software. Immuno-labelling for mucin 2 and chromogranin A identified goblet cells and enteroendocrine cells, respectively. CC3 labelling was used to identify apoptotic cells. For each marker, positive stained cells per crypt-villus unit were counted to generate an average number of positive cells per crypt-villus unit per animal. At least 3 animals of each genotype and at least 20 crypt-villi units were assessed per animal. Nuclear $\beta$-catenin was quantified to assess Wnt pathway activation. Images from at least three animals of each genotype were assessed and for each region (crypt or villus) over 1000 cells were assessed for co-localization of DAPI and nuclear $\beta$-catenin. Results were plotted using Graphpad Prism. Heat maps were created using R software [74].

\section{Western blot analysis}

For Western Blot analysis $1 \times 10^{6}$ cells (MCF-7, HT29, Colo201, Colo320 and HEK293T) were grown. Homogenisation of cells was performed in RIPA buffer (50 $\mathrm{mM}$ Tris- $\mathrm{HCl} \mathrm{pH} 8.0,150 \mathrm{mM} \mathrm{NaCl}, 1 \%$ Triton X-100, $0.5 \%$ sodium deoxycholate, $0.1 \%$ SDS) in the presence of 2x protease-phosphatase inhibitor cocktail (Halt cocktail, Pierce) at $4^{\circ} \mathrm{C}$. After centrifugation at $13,000 \mathrm{rpm}$ at $4^{\circ} \mathrm{C}$ for $30 \mathrm{~min}$, supernatants, consisting of the cleared lysate, were collected and stored at $-80^{\circ} \mathrm{C}$. The concentration of total protein in lysates was determined using the CB-X Protein Assay (G-Biosciences). Volumes of lysate, containing $5 \mu \mathrm{g}$ protein, were mixed with equal amounts of 2x Laemmli SDS loading buffer (Sigma) and were denatured by heating to $95^{\circ} \mathrm{C}$ for $5 \mathrm{~min}$. Denatured lysates were centrifuged at $13,000 \mathrm{rpm}$ before being electrophoresed on a $10 \%$ SDS polyacrylamide resolving gel (Mini-Protean 3, BioRad). Proteins were transferred to a PVDF membrane (Immobilion P, Millipore) by electroblotting (Mini-Protean 3 , Bio-Rad) and membranes were incubated with blocking buffer (5\% non-fat milk in TBS/0.1\% Tween-20 (TBST) for 1 hour at room temperature. Membranes were incubated (2 $\mathrm{hr}$ ) with primary antibodies in blocking buffer: E-Cadherin (BD; 1:3,000) and $\beta$-Actin (Abcam, 1:20,000). After $3 \mathrm{x}$ 5 minute washes with TBST, membranes were incubated with HRP-conjugated secondary antibodies (Dako, 1:2000) for $1 \mathrm{hr}$ at RT in blocking buffer. Membranes were washed ( 3 x 5 min) with TBST, signals were developed for using an enhanced chemo-luminescence system (Promega, UK).

\section{Adenoma culture and adenovirus transfection}

Adenoma culture was adapted from $[15,75]$. Briefly, caecal (colonic) tumors were utilised due to their larger size, cut into small pieces in sterile PBS $\left(4^{\circ} \mathrm{C}\right)$, washed to remove debris and incubated in 5mM EDTA in PBS for 10 min at room temperature, shaken vigorously and washed using PBS (without calcium and magnesium) to remove EDTA. Cells were incubated in Trypsin $(0.5 \mathrm{mg} / \mathrm{ml})$, supplemented with $100 \mathrm{U}$ DNase (at $37^{\circ} \mathrm{C}$ for 30 minutes) washed in ADF medium (DMEM/F12, Invitrogen, UK) and warmed to $37^{\circ} \mathrm{C}$. The cell solution was shaken vigorously, centrifuged at 1200rpm for 3 minutes and the supernatant removed. The remaining adenoma cells were then re-suspended in ADF, dissociated, and pelleted five times, with adenoma cells being passed through a $70 \mu \mathrm{m}$ cell strainer, washed and re-suspended in $1 \mathrm{ml} \mathrm{ADF}$, and counted using a NucleoCounter (Chemotech) that assessed cell number, the proportion of single cells and viability. 3000 viable cells in $35 \mu \mathrm{l}$ were combined with $35 \mu 1$ matrigel per well and cultured on glass coverslips in 24-well plates. The plates were incubated at $37^{\circ} \mathrm{C}$ for 10 minutes to solidify the matrigel, then $500 \mu$ of ADF supplemented with N2 (Invitrogen, UK), B27 (Invitrogen, UK), EGF (5ng.ml-1 ${ }^{-1}$ Peprotech) and Noggin $\left(0.1 \mu \mathrm{g} \cdot \mathrm{ml}^{-1}\right.$, Peprotech), without R-Spondin. Adenoma culture could be maintained by weekly passage and plating in fresh matrigel. Adenovirus expressing Cre recombinase under the cytomegalovirus (CMV) promoter (Ad-Cre, Vector Biolabs) was used at a multiplicity of infection (MOI) of 500 and transfected on the day of adenoma harvesting culture before being embedded in matrigel. Immunolabelling with an anti-Cre recombinase antibody as used to detect Cre recombinase expression and anti E-cadherin antibody to detect loss of E-cadherin expression.

As interpretation of immunolabelling results can be subjective, a method was developed to provide an objective assessment of the labelling of individual markers. For each marker, at least 4 adenomas were assessed from each of the $A p c^{\text {fllfl}} C \mathrm{Cdh} 1^{\text {fl/f }} \operatorname{Lgr} 5 \mathrm{CreER} \mathrm{R}^{T 2} \mathrm{Ad}-$ Cre- and Apc $c^{A l f l} C d h 1^{f l f} L g r 5 C r e E R^{T 2}$ Ad-Cre+ groups. Supplementary Figure S12 outlines the methodology. Using Olympus Fluoview viewer software the adenoma was divided into zones: an outer zone where there was no membrane bound E-cadherin, an inner zone where there was normal appearance of membrane bound E-cadherin, and a transition zone where cells had a mixture of intact and disrupted E-cadherin. Based on distance from the centre of the adenoma, the inner zone was divided into two: a central ' $50 \%$ ' area and a surrounding ' $100 \%$ ' area. The rationale for the 50/100 
division was the 3D structure of the adenomas could results in inconsistent labelling of the central area with some central cores hollow and thus barely labelled, and others strongly labelled. Apc $c^{f l / l} C_{d h} 1^{f l f l} \operatorname{Lgr}^{2} C r e E R^{T 2} \mathrm{Ad}-$ Cre- adenomas did not have a transition or outer zone as all cells had intact membrane bound E-cadherin. Once the adenoma was divided into zones, only the channel with the marker of interest was selected and this image was exported to ImageJ where it was converted to grayscale. ImageJ tools were then used to measure the fluorescence of the cells in each area and cells were manually counted to calculate a 'mean fluorescence per cell' measurement for each zone. For each marker at least 1000 cells were assessed, but often more (over 7000 in some cases). For each image the mean fluorescence per cell in each zone was normalized to that in the $100 \%$ zone. For the Wnt targets $\beta$-catenin and Axin2, the location of the marker within the cell was also assessed. Using Olympus Fluoview software, DAPI was colored red and the marker of interest green. When the two were colocalised, the nucleus appeared yellow. For each cell the marker of choice was scored as to whether it was predominantly cytoplasmic, predominantly nuclear or whether there was equal nuclear and cytoplasmic labelling. A cell with predominantly cytoplasmic staining was assigned a value of 0 , equal cytoplasmic and nuclear staining obtained a value of 1 , and predominant nuclear staining was assigned a value of 2 . Thus a total value could be generated for each area that reflected the proportion of cells with nuclear localization of the marker. These data was represented as heatmaps generated using $\mathrm{R}$ software. For the average fluorescence per cell heat maps data was underwent a Log2 transformation.

For time-lapse microscopy of adenoma culture was on glass coverslips cultured in humidified imaging chamber at $37^{\circ} \mathrm{C}$ with a Zeiss LSM510 META confocal microscope and LSM5 software. Images were captured every 2 minutes between 24 and 72 hrs using a 10x objective. Files (.1sm) were loaded into FIJI (http:// fiji.sc/) and converted to a stack (.tiff) and saved as an uncompressed .avi movie file with 29 frames per second, and representative frames presented.

\section{Adenovirus expressing murine E-cadherin}

CMV promoter driven adenovirus expressing either murine wild-type $\left(C d h 1^{W T}\right)$ or an EC1 domain mutated cDNA, were combined with an IRES for the fluorescent reporter RFP (Vector Biolabs). The two mutations introduced into the EC1 domain were a tryptophan to alanine (W2A), involved in the strand swapping mechanism, and a mutation of the $\mathrm{Ca}^{2+}$ dependent binding site that introduces a bulky tryptophan into the binding site where there is normally a serine residue (S78W). The denoted $C d h 1^{W 2 A, S 78 Y}$ is abbreviated to $C d h 1^{M u t}$.

\section{Flow cytometry validation of E-cadherin binding in MCF7 cells}

MCF-7 cells were infected with adenovirus expressing wild-type murine E-cadherin (Ad-Cdh1-WT) or a mutant expressing (Ad-Cdh1-Mut) at an $\mathrm{MOI}=100$, and cell-sorted with a BD-FACSDiva 8.0, 3-4 days after transfection in order to enrich for RFP positive cells. Sorted populations were cultured for a further 2 days, to enhance the yield of $C d h 1$ expressing cells, before E-cadherin binding. Cells were detached from the bottom of cell culture flasks with $5 \mathrm{mM}$ EDTA in PBS, re-suspended in DMEM+10\% FCS media and grown in $15 \mathrm{ml}$ tubes for another $6 \mathrm{hr}$ at $37^{\circ} \mathrm{C}$ Cells were then centrifuged at $1000 \mathrm{rpm}$, re-suspended in DMEM and transferred to $1.7 \mathrm{ml}$ centrifuge tubes pre-coated with $0.1 \%$ BSA. Cells were re-suspended in PBS, with and without $\mathrm{His}_{6}$ tag labelled recombinant human Fc-Ecadherin (R\&D Systems, $100 \mathrm{ug} / \mathrm{ml}$ ) or recombinant Fc-ECadherin with $5 \mathrm{mM}$ EDTA, and were incubated for $(1 \mathrm{hr}$, $\left.4{ }^{\circ} \mathrm{C}\right)$. Subsequently, cells were washed once with PBS and labeled with a mouse anti-His ${ }_{6}$ tag antibody (1:200, Roche) for $30 \mathrm{~min}$ at RT. Cells were then washed and incubated with a secondary goat anti-mouse Alexa405 antibody (1:1000, $30 \mathrm{~min}, \mathrm{RT})$. Binding of human recombinant FcE-cadherin was quantified by flow cytometry (Cyan ADP analyser, Beckman Coulter).

\section{Cdh1 complementation in adenomas}

$$
A p c^{f l f l} \mathrm{Cdh}^{+/+} \operatorname{Lgr} 5 \mathrm{CreER} R^{T 2} \text { and } A p c^{A / f l} \mathrm{Cdh} 1^{f / f l}
$$
Lgr 5 CreER ${ }^{T 2}$ adenomas were infected with Ad-Cre-GFP (MOI of 100) alone or in combination with Ad-Cdh1-WTRFP (MOI of 100) or Ad-Cdh1-Mut-RFP (MOI of 100). In order to increase the infection efficiency, adenoviruses were pre-incubated with adenomas in single cell suspension for $10 \mathrm{~min}$ at $37^{\circ} \mathrm{C}$. Subsequently, adenomas were seeded in matrigel at a density of 10,000 cells per well (24 well plates) and adenoviruses added to the culture medium for a further 6 days. Culture supernatant was then aspirated from each well and the adenomas were washed with ice-cold PBS. Cells were centrifuged at $1000 \mathrm{rpm}$ and washed twice with PBS at $4{ }^{\circ} \mathrm{C}$. Cell pellets were then fixed in $4 \%(\mathrm{v} / \mathrm{v})$ formaldehyde in PBS (15 min). Cells were blocked and permeabilized in PBS with Triton $0.5 \%(\mathrm{v} / \mathrm{v})$ and $10 \%(\mathrm{v} / \mathrm{v})$ goat serum (30 min). Fixed and permeabilized cells were labeled with primary antibodies $\beta$-catenin and E-cadherin (BD, 1:300, 1 hr, RT). Labeled and washed cells were then incubated with secondary antibodies, either goat anti-mouse $\mathrm{IgG}_{1}$ Alexa405 or goat anti-mouse $\operatorname{IgG}_{2 \mathrm{a}}$ Alexa647 (Invitrogen, 1:500, $30 \mathrm{~min}$ ). For image stream analysis, $A p c^{4 / 4} \mathrm{Cdh}^{+/+} \operatorname{Lgr} 5 \mathrm{CreER} \mathrm{R}^{T 2}$ and $A p c^{4 / A} C d h 1^{f l / f} \operatorname{Lg} 5 C r e E R^{T 2}$ adenoma organoid cell suspensions were processed, fixed and labeled as above, except for dilutions of mouse anti- $\beta$-catenin (BD, 1:500), and secondary antibody, goat anti-mouse $\operatorname{IgG}_{1}$ Alexa647 
(Invitrogen, 1:1000). Adenoma cells transfected with adenovirus were analysed with an Amnis Image Stream ${ }^{\mathrm{X}}$ Mark II using adapted IDEAS software, include the Dilate mask for similarity, where additional DAPI mask pixels are added.

\section{ACKNOWLEDGMENTS}

We thank Kevin Maloy, Andrew Silver and Elisabeth Robertson for discussion. Linda Randall (mouse), Madeleine Hipp (flow cytometry) and Andrea Baines (manuscript) for technical assistance.

\section{CONFLICTS OF INTEREST}

None.

\section{GRANT SUPPORT}

We thank Cancer Research UK (A429- ABH) and Rhodes Trust (JM) for funding.

\section{Author contributions}

Experiments conceived by $\mathrm{ABH}$ and $\mathrm{JM}$, mouse breeding and all phenotypic analysis by JM, imaging and flow cytometry by $\mathrm{CB}, \mathrm{SC}$ and JM, gene expression $\mathrm{DB}$ and $\mathrm{JM}$, embryology $\mathrm{JH}$ and $\mathrm{JM}$, genotyping by $\mathrm{EC}$ and MS, histopathology HM, E-cadherin cloning HJH and the manuscript was written by JM, CB and ABH. All authors approved the manuscript.

\section{REFERENCES}

1. Canel M, Serrels A, Frame MC and Brunton VG. E-cadherin-integrin crosstalk in cancer invasion and metastasis. J Cell Sci. 2013; 126:393-401.

2. Lecuit $\mathrm{T}$ and Yap AS. E-cadherin junctions as active mechanical integrators in tissue dynamics. Nat Cell Biol. 2015; 17:533-539.

3. Vendome J, Posy S, Jin X, Bahna F, Ahlsen G, Shapiro L and Honig B. Molecular design principles underlying betastrand swapping in the adhesive dimerization of cadherins. Nat Struct Mol Biol. 2011; 18:693-700.

4. Wu Y, Vendome J, Shapiro L, Ben-Shaul A and Honig B. Transforming binding affinities from three dimensions to two with application to cadherin clustering. Nature. 2011; 475:510-513.

5. Niessen CM, Leckband D and Yap AS. Tissue organization by cadherin adhesion molecules: dynamic molecular and cellular mechanisms of morphogenetic regulation. Physiol Rev. 2011; 91:691-731.

6. Chen YT, Stewart DB and Nelson WJ. Coupling assembly of the E-cadherin/beta-catenin complex to efficient endoplasmic reticulum exit and basal-lateral membrane targeting of E-cadherin in polarized MDCK cells. J Cell Biol. 1999; 144:687-699.

7. Fujita Y, Krause G, Scheffner M, Zechner D, Leddy HE, Behrens J, Sommer T and Birchmeier W. Hakai, a c-Cbllike protein, ubiquitinates and induces endocytosis of the E-cadherin complex. Nat Cell Biol. 2002; 4:222-231.

8. Hartsock A and Nelson WJ. Competitive regulation of E-cadherin juxtamembrane domain degradation by $\mathrm{p} 120$ catenin binding and Hakai-mediated ubiquitination. PLoS One. 2012; 7:e37476.

9. Smalley-Freed WG, Efimov A, Burnett PE, Short SP, Davis MA, Gumucio DL, Washington MK, Coffey RJ and Reynolds AB. p120-catenin is essential for maintenance of barrier function and intestinal homeostasis in mice. J Clin Invest. 2010; 120:1824-1835.

10. Kourtidis A, Ngok SP, Pulimeno P, Feathers RW, Carpio LR, Baker TR, Carr JM, Yan IK, Borges S, Perez EA, Storz P, Copland JA, Patel T, Thompson EA, Citi S and Anastasiadis PZ. Distinct E-cadherin-based complexes regulate cell behaviour through miRNA processing or Src and p120 catenin activity. Nat Cell Biol. 2015; 17:1145-1157.

11. Clevers $\mathrm{H}$ and Nusse $\mathrm{R}$. Wnt/ $\beta$-catenin signaling and disease. Cell. 2012; 149:1192-1205.

12. Li VS, Ng SS, Boersema PJ, Low TY, Karthaus WR, Gerlach JP, Mohammed S, Heck AJ, Maurice MM, Mahmoudi $\mathrm{T}$ and Clevers $\mathrm{H}$. Wnt signaling through inhibition of $\beta$-catenin degradation in an intact Axin1 complex. Cell. 2012; 149:1245-1256.

13. Simons BD and Clevers H. Stem cell self-renewal in intestinal crypt. Exp Cell Res. 2011; 317:2719-2724.

14. Barker N, van Es J, Kuipers J, Kujala P, van den Born M, Cozijnsen M, Haegebarth A, Korving J, Begthel H, Peters $\mathrm{P}$ and Clevers H. Identification of stem cells in small intestine and colon by marker gene Lgr5. Nature. 2007; 449:1003-1007.

15. Sato T, van Es JH, Snippert HJ, Stange DE, Vries RG, van den Born M, Barker N, Shroyer NF, van de Wetering M and Clevers H. Paneth cells constitute the niche for Lgr5 stem cells in intestinal crypts. Nature. 2011; 469:415-418.

16. Snippert HJ, van der Flier LG, Sato T, van Es JH, van den Born M, Kroon-Veenboer C, Barker N, Klein AM, van Rheenen J, Simons BD and Clevers H. Intestinal crypt homeostasis results from neutral competition between symmetrically dividing Lgr5 stem cells. Cell. 2010; 143:134-144.

17. Sancho E, Batlle E and Clevers H. Signaling pathways in intestinal development and cancer. Annu Rev Cell Dev Biol. 2004; 20:695-723.

18. Pinto D and Clevers H. Wnt, stem cells and cancer in the intestine. Biol Cell. 2005; 97:185-196.

19. Dow LE, O'Rourke KP, Simon J, Tschaharganeh DF, van Es JH, Clevers H and Lowe SW. Apc Restoration Promotes Cellular Differentiation and Reestablishes Crypt Homeostasis in Colorectal Cancer. Cell. 2015; 161:1539-1552. 
20. Schuijers J and Clevers H. Adult mammalian stem cells: the role of Wnt, Lgr5 and R-spondins. EMBO J. 2012; 31:2685-2696.

21. Giannakis $\mathrm{M}$, Hodis E, Jasmine $\mathrm{Mu} \mathrm{X}$, Yamauchi $\mathrm{M}$, Rosenbluh J, Cibulskis K, Saksena G, Lawrence MS, Qian ZR, Nishihara R, Van Allen EM, Hahn WC, Gabriel $\mathrm{SB}$, et al. RNF43 is frequently mutated in colorectal and endometrial cancers. Nat Genet. 2014; 46:1264-1266.

22. Network CGA. Comprehensive molecular characterization of human colon and rectal cancer. Nature. 2012; 487:330-337.

23. Seshagiri S, Stawiski EW, Durinck S, Modrusan Z, Storm EE, Conboy CB, Chaudhuri S, Guan Y, Janakiraman V, Jaiswal BS, Guillory J, Ha C, Dijkgraaf GJ, et al. Recurrent R-spondin fusions in colon cancer. Nature. 2012; 488:660-664.

24. Sansom OJ, Reed KR, Hayes AJ, Ireland H, Brinkmann H, Newton IP, Batlle E, Simon-Assmann P, Clevers H, Nathke IS, Clarke AR and Winton DJ. Loss of Apc in vivo immediately perturbs Wnt signaling, differentiation, and migration. Genes Dev. 2004; 18:1385-1390.

25. Huels DJ, Ridgway RA, Radulescu S, Leushacke M, Campbell AD, Biswas S, Leedham S, Serra S, Chetty R, Moreaux G, Parry L, Matthews J, Song F, et al. E-cadherin can limit the transforming properties of activating betacatenin mutations. EMBO J. 2015.

26. Smith CG, Fisher D, Harris R, Maughan TS, Phipps AI, Richman S, Seymour M, Tomlinson I, Rosmarin D, Kerr D, Chan AT, Peters U, Newcomb PA, et al. Analyses of 7,635 Patients with Colorectal Cancer Using Independent Training and Validation Cohorts Show That rs9929218 in CDH1 Is a Prognostic Marker of Survival. Clin Cancer Res. 2015.

27. Study C, Houlston RS, Webb E, Broderick P, Pittman AM, Di Bernardo MC, Lubbe S, Chandler I, Vijayakrishnan J, Sullivan K, Penegar S, Colorectal Cancer Association Study C, Carvajal-Carmona L, et al. Meta-analysis of genomewide association data identifies four new susceptibility loci for colorectal cancer. Nat Genet. 2008; 40:1426-1435.

28. el Marjou F, Janssen K, Chang B, Li M, Hindie V, Chan L, Louvard D, Chambon P, Metzger D and Robine S. Tissuespecific and inducible Cre-mediated recombination in the gut epithelium. Genesis. 2004; 39:186-193.

29. Bondow BJ, Faber ML, Wojta KJ, Walker EM and Battle MA. E-cadherin is required for intestinal morphogenesis in the mouse. Dev Biol. 2012; 371:1-12.

30. Al Alam D, Green M, Tabatabai Irani R, Parsa S, Danopoulos S, Sala FG, Branch J, El Agha E, Tiozzo C, Voswinckel R, Jesudason EC, Warburton D and Bellusci S. Contrasting expression of canonical Wnt signaling reporters TOPGAL, BATGAL and Axin2(LacZ) during murine lung development and repair. PLoS One. 2011; 6:e23139.

31. Haines J, Johnson V, Pack K, Suraweera N, Slijepcevic P, Cabuy E, Coster M, Ilyas M, Wilding J, Sieber O, Bodmer W, Tomlinson I and Silver A. Genetic basis of variation in adenoma multiplicity in ApcMin/+ Mom1S mice. Proc Natl Acad Sci U S A. 2005; 102:2868-2873.

32. Smits R, Ruiz P, Diaz-Cano S, Luz A, Jagmohan-Changur S, Breukel C, Birchmeier C, Birchmeier W and Fodde R. E-cadherin and adenomatous polyposis coli mutations are synergistic in intestinal tumor initiation in mice. Gastroenterology. 2000; 119:1045-1053.

33. Barker N, Ridgway RA, van Es JH, van de Wetering M, Begthel H, van den Born M, Danenberg E, Clarke AR, Sansom OJ and Clevers H. Crypt stem cells as the cellsof-origin of intestinal cancer. Nature. 2009; 457:608-611.

34. Barker N, van Oudenaarden A and Clevers H. Identifying the stem cell of the intestinal crypt: strategies and pitfalls. Cell Stem Cell. 2012; 11:452-460.

35. Sato T, Vries RG, Snippert HJ, van de Wetering M, Barker N, Stange DE, van Es JH, Abo A, Kujala P, Peters PJ and Clevers H. Single Lgr5 stem cells build crypt-villus structures in vitro without a mesenchymal niche. Nature. 2009; 459:262-265.

36. Cheung EC, Athineos D, Lee P, Ridgway RA, Lambie W, Nixon C, Strathdee D, Blyth K, Sansom OJ and Vousden $\mathrm{KH}$. TIGAR is required for efficient intestinal regeneration and tumorigenesis. Dev Cell. 2013; 25:463-477.

37. Larue L, Ohsugi M, Hirchenhain $J$ and Kemler R. E-cadherin null mutant embryos fail to form a trophectoderm epithelium. Proc Natl Acad Sci U S A. 1994; 91:8263-8267.

38. Madison BB, Dunbar L, Qiao XT, Braunstein K, Braunstein $\mathrm{E}$ and Gumucio DL. Cis elements of the villin gene control expression in restricted domains of the vertical (crypt) and horizontal (duodenum, cecum) axes of the intestine. J Biol Chem. 2002; 277:33275-33283.

39. Madison BB, Braunstein K, Kuizon E, Portman K, Qiao XT and Gumucio DL. Epithelial hedgehog signals pattern the intestinal crypt-villus axis. Development. 2005; 132:279-289.

40. Schneider MR, Dahlhoff M, Horst D, Hirschi B, Trülzsch K, Müller-Höcker J, Vogelmann R, Allgäuer M, Gerhard M, Steininger S, Wolf E and Kolligs FT. A key role for E-cadherin in intestinal homeostasis and Paneth cell maturation. PLoS One. 2010; 5:e14325.

41. Shao J and Sheng H. Amphiregulin promotes intestinal epithelial regeneration: roles of intestinal subepithelial myofibroblasts. Endocrinology. 2010; 151:3728-3737.

42. Smalley-Freed WG, Efimov A, Short SP, Jia P, Zhao Z, Washington MK, Robine S, Coffey RJ and Reynolds AB. Adenoma formation following limited ablation of p120catenin in the mouse intestine. PLoS One. 2011; 6:e19880.

43. Solanas G, Cortina C, Sevillano M and Batlle E. Cleavage of E-cadherin by ADAM10 mediates epithelial cell sorting downstream of EphB signalling. Nat Cell Biol. 2011; 13:1100-1107.

44. Cortina C, Palomo-Ponce S, Iglesias M, Fernández-Masip JL, Vivancos A, Whissell G, Humà M, Peiró N, Gallego 
L, Jonkheer S, Davy A, Lloreta J, Sancho E and Batlle E. EphB-ephrin-B interactions suppress colorectal cancer progression by compartmentalizing tumor cells. Nat Genet. 2007; 39:1376-1383.

45. Johnson P and Ruffell B. CD44 and its role in inflammation and inflammatory diseases. Inflamm Allergy Drug Targets. 2009; 8:208-220.

46. Tian H, Biehs B, Chiu C, Siebel CW, Wu Y, Costa M, de Sauvage FJ and Klein OD. Opposing activities of Notch and Wnt signaling regulate intestinal stem cells and gut homeostasis. Cell reports. 2015; 11:33-42.

47. Muñoz Descalzo S and Martinez Arias A. The structure of Wntch signalling and the resolution of transition states in development. Semin Cell Dev Biol. 2012; 23:443-449.

48. Consortium UIG, Barrett JC, Lee JC, Lees CW, Prescott NJ, Anderson CA, Phillips A, Wesley E, Parnell K, Zhang H, Drummond H, Nimmo ER, Massey D, et al. Genome-wide association study of ulcerative colitis identifies three new susceptibility loci, including the HNF4A region. Nat Genet. 2009; 41:1330-1334.

49. Muise AM, Walters TD, Glowacka WK, Griffiths AM, Ngan BY, Lan H, Xu W, Silverberg MS and Rotin D. Polymorphisms in E-cadherin (CDH1) result in a mislocalised cytoplasmic protein that is associated with Crohn's disease. Gut. 2009; 58:1121-1127.

50. Stemmler MP, Hecht A, Kinzel B and Kemler R. Analysis of regulatory elements of E-cadherin with reporter gene constructs in transgenic mouse embryos. Dev Dyn. 2003; 227:238-245.

51. von Burstin J, Eser S, Paul MC, Seidler B, Brandl M, Messer M, von Werder A, Schmidt A, Mages J, Pagel P, Schnieke A, Schmid RM, Schneider G and Saur D. E-cadherin regulates metastasis of pancreatic cancer in vivo and is suppressed by a SNAIL/HDAC1/HDAC2 repressor complex. Gastroenterology. 2009; 137:361-371, 371.e361-365.

52. Peinado H, Olmeda D and Cano A. Snail, Zeb and bHLH factors in tumour progression: an alliance against the epithelial phenotype? Nat Rev Cancer. 2007; 7:415-428.

53. Bolós V, Peinado H, Pérez-Moreno MA, Fraga MF, Esteller $\mathrm{M}$ and Cano A. The transcription factor Slug represses E-cadherin expression and induces epithelial to mesenchymal transitions: a comparison with Snail and E47 repressors. J Cell Sci. 2003; 116:499-511.

54. Cano A, Pérez-Moreno MA, Rodrigo I, Locascio A, Blanco MJ, del Barrio MG, Portillo F and Nieto MA. The transcription factor snail controls epithelial-mesenchymal transitions by repressing E-cadherin expression. Nat Cell Biol. 2000; 2:76-83.

55. Yang J, Mani SA, Donaher JL, Ramaswamy S, Itzykson RA, Come C, Savagner P, Gitelman I, Richardson A and Weinberg RA. Twist, a master regulator of morphogenesis, plays an essential role in tumor metastasis. Cell. 2004; 117:927-939.
56. Fouquet S, Lugo-Martínez VH, Faussat AM, Renaud F, Cardot P, Chambaz J, Pinçon-Raymond $\mathrm{M}$ and Thenet $\mathrm{S}$. Early loss of E-cadherin from cell-cell contacts is involved in the onset of Anoikis in enterocytes. J Biol Chem. 2004; 279:43061-43069.

57. Korswagen HC, Herman MA and Clevers HC. Distinct beta-catenins mediate adhesion and signalling functions in C. elegans. Nature. 2000; 406:527-532.

58. Heasman J, Crawford A, Goldstone K, Garner-Hamrick P, Gumbiner B, McCrea P, Kintner C, Noro CY and Wylie C. Overexpression of cadherins and underexpression of betacatenin inhibit dorsal mesoderm induction in early Xenopus embryos. Cell. 1994; 79:791-803.

59. Sanson B, White P and Vincent JP. Uncoupling cadherinbased adhesion from wingless signalling in Drosophila. Nature. 1996; 383:627-630.

60. Stockinger A, Eger A, Wolf J, Beug $\mathrm{H}$ and Foisner R. E-cadherin regulates cell growth by modulating proliferation-dependent beta-catenin transcriptional activity. J Cell Biol. 2001; 154:1185-1196.

61. Orsulic S, Huber O, Aberle H, Arnold S and Kemler R. E-cadherin binding prevents beta-catenin nuclear localization and beta-catenin/LEF-1-mediated transactivation. J Cell Sci. 1999; 112 :1237-1245.

62. Kuphal F and Behrens J. E-cadherin modulates Wntdependent transcription in colorectal cancer cells but does not alter Wnt-independent gene expression in fibroblasts. Exp Cell Res. 2006; 312:457-467.

63. Perl A, Wilgenbus P, Dahl U, Semb H and Christofori G. A causal role for E-cadherin in the transition from adenoma to carcinoma. Nature. 1998; 392:190-193.

64. Herzig M, Savarese F, Novatchkova M, Semb H and Christofori G. Tumor progression induced by the loss of E-cadherin independent of beta-catenin/Tcf-mediated Wnt signaling. Oncogene. 2007; 26:2290-2298.

65. Benusiglio PR, Malka D, Rouleau E, De Pauw A, Buecher B, Nogues C, Fourme E, Colas C, Coulet F, Warcoin M, Grandjouan S, Sezeur A, Laurent-Puig P, et al. CDH1 germline mutations and the hereditary diffuse gastric and lobular breast cancer syndrome: a multicentre study. Journal of medical genetics. 2013; 50:486-489.

66. Guilford P, Humar B and Blair V. Hereditary diffuse gastric cancer: translation of $\mathrm{CDH} 1$ germline mutations into clinical practice. Gastric cancer. 2010; 13:1-10.

67. Suriano G, Oliveira MJ, Huntsman D, Mateus AR, Ferreira P, Casares F, Oliveira C, Carneiro F, Machado JC, Mareel $\mathrm{M}$ and Seruca R. E-cadherin germline missense mutations and cell phenotype: evidence for the independence of cell invasion on the motile capabilities of the cells. Hum Mol Genet. 2003; 12:3007-3016.

68. Shibata H, Toyama K, Shioya H, Ito M, Hirota M, Hasegawa $\mathrm{S}$, Matsumoto H, Takano H, Akiyama T, Toyoshima K, Kanamaru R, Kanegae Y, Saito I, Nakamura Y, Shiba K and Noda T. Rapid colorectal adenoma formation initiated 
by conditional targeting of the Apc gene. Science. 1997; 278:120-123.

69. Derksen P, Liu X, Saridin F, van der Gulden H, Zevenhoven J, Evers B, van Beijnum J, Griffioen A, Vink J, Krimpenfort P, Peterse J, Cardiff R, Berns A and Jonkers J. Somatic inactivation of E-cadherin and p53 in mice leads to metastatic lobular mammary carcinoma through induction of anoikis resistance and angiogenesis. Cancer Cell. 2006; 10:437-449.

70. Srinivas S, Watanabe T, Lin C, William C, Tanabe Y, Jessell $\mathrm{T}$ and Costantini F. Cre reporter strains produced by targeted insertion of EYFP and ECFP into the ROSA26 locus. BMC Dev Biol. 2001; 1:4.

71. Vandesompele J, De Preter K, Pattyn F, Poppe B, Van Roy N, De Paepe A and Speleman F. Accurate normalization of real-time quantitative RT-PCR data by geometric averaging of multiple internal control genes. Genome Biol. 2002; 3:RESEARCH0034.

72. Du P, Kibbe WA and Lin SM. lumi: a pipeline for processing Illumina microarray. Bioinformatics. 2008; 24:1547-1548.

73. Tusher VG, Tibshirani R and Chu G. Significance analysis of microarrays applied to the ionizing radiation response. Proc Natl Acad Sci U S A. 2001; 98:5116-5121.

74. R Development Core Team. (2008). R: A language and environment for statistical computing. (Vienna, Austria: R Foundation for Statistical Computing).

75. Sato T, Stange DE, Ferrante M, Vries RG, Van Es JH, Van den Brink S, Van Houdt WJ, Pronk A, Van Gorp J, Siersema $\mathrm{PD}$ and Clevers H. Long-term expansion of epithelial organoids from human colon, adenoma, adenocarcinoma, and Barrett's epithelium. Gastroenterology. 2011; 141:1762-1772. 